\title{
A Narrative Review of Slow Medicine Outcomes
}

\author{
Rani Marx, PhD, MPH and James G. Kabn, MD, MPH
}

Background: Primary care practice in the United States suffers from short consultation duration and distracting electronic health record tasks. This leads to patient and physician dissatisfaction and physician burnout, as well as potentially unnecessary referrals and interventions. Slow medicine - providing longer and higher-quality consultations - has been proposed to improve medical care quality and patient outcomes. However, definitive outcome data for US settings are lacking.

Methods: Following a structured narrative approach, we identified, reviewed, and synthesized existing reports (peer-reviewed and grey) to determine if there is sufficient evidence to support systematic evaluation of slow medicine in the US. We assessed whether longer versus shorter face-to-face primary care consultations were associated with quantitative patient outcomes including utilization; prevention; visit elements; medication adherence and prescription volume; mortality; and costs.

Results: We found suggestive evidence of substantial savings in hospital use and costs in varied geographic and clinical settings. However, this evidence lacks investigative rigor such as convincing prospective or natural randomization.

Conclusions: With potentially significant health and financial benefits from slow medicine and little risk to subjects, randomized trials, natural experiments, and mixed methods evaluations are strongly indicated. We discuss the need for modified payment practices to facilitate a slow medicine approach. (J Am Board Fam Med 2021;34:1249-1264.)

Keywords: Consultation, Narrative Review, Physician-Patient Relations, Primary Health Care, Slow Medicine

\section{Background}

The time-constrained primary care delivery model that dominates United States (US) health care pleases neither clinicians nor patients. Although both groups desire high-quality consultations, visits are typically brief, focused on directed clinical data gathering, with the physician tethered to a computer. ${ }^{1-3}$ The financing structure of US health care drives these time constraints, ${ }^{4-7}$ in particular Medicare's "relative value unit" payment model. ${ }^{8}$ Diagnostic and therapeutic advances, proliferation of clinical practice guidelines, increased preventive service demands on primary care physicians, and federal reporting requirements

This article was externally peer reviewed.

Submitted 31 March 2021; revised 30 April 2021; accepted 21 July 2021.

From Initiative for Slow Medicine, Berkeley, CA (RM, JGK); Institute for Health Policy Studies, University of California, San Francisco (JGK).

Funding: none.

Conflict of interest: none.

Corresponding author: Rani Marx, $\mathrm{PhD}, \mathrm{MPH}$, Initiative for Slow Medicine, 81 Alvarado Road, Berkeley, CA 94705 (E-mail: ranimarx1960@gmail.com). contribute to increasingly circumscribed patientphysician interaction..$^{8-10}$

The expanding demands of the electronic health record (EHR) further erode time. ${ }^{1-13}$ The EHR increases physician workload, both during visits and after hours, but diminishes face-to-face and handson interactions between doctor and patient (detail in Appendix). Designed largely for billing purposes, the EHR has inadvertently impaired clinical interaction. Many EHR characteristics are unique to the US, with greater complexity and requirements even for the same vendor's product. ${ }^{12}$ Only about half of physician time is spent on direct interaction with patients, even less if EHR tasks in the patient's presence are strictly excluded. ${ }^{1,2,14}$ The complexity of coding using the relative value units (RVUs) demanded of physicians to reimburse for Medicare patients may further erode consultation duration and unfairly penalize practitioners who are less knowledgeable or creative about their use.

"Fast medicine" can backfire clinically. It may preclude sufficient time for appropriate exploratory discussion and contemplation, yielding an array of undesirable outcomes: impaired 
physician-patient communication; missed or incorrect diagnoses; unneeded tests, procedures, and specialist consultations; overprescription; avoidable emergency visits and hospitalizations; medical errors; inability to assess and address the social determinants of health that influence a patient's prognosis and care plan; physician and patient dissatisfaction; and a rising epidemic of physician burnout. 1,6,15-22

Myriad publications, organizations, and movements describe the underlying causes and offer tools and resources for addressing this erosion of time (detail in Appendix). Some focus on particular settings or populations, while others are more broadly targeted. $^{23-29}$ However, most proposed solutions function within our existing health care structure and the accompanying time-constrained clinical consultation.

"Slow medicine" is one promising approach to reclaim quality consultation time. The idea originated in $2002^{30}$ inspired by the 1986 Italian slow food movement and other slow movements. ${ }^{31,32}$ In 2011, Italy established a Slow Medicine Society ${ }^{33}$ aligned closely with the Choosing Wisely movement ${ }^{24}$ and convened a conference. ${ }^{34}$ The Netherlands and Brazil have also published slow medicine precepts.

The central concept is to take the time needed for the clinical task at hand. Slow medicine proponents suggest that giving doctors enough time to thoroughly learn about their patients (medically, psychologically, and socially) will enable an accurate diagnosis and effective treatment, improve patient outcomes, increase patient and physician satisfaction, and reduce costs. ${ }^{30-36}$

Very few clinical settings embrace slow medicine. Concierge medicine and direct primary care (CM/DPC) are the prime examples, structurally diverging from fast medical practice. Physician and patient desire for more face-to-face time helps explain their appeal. Both models charge patients monthly or annual fees; have smaller patient panels than usual primary care; and offer easier access and longer, often unlimited, appointments. ${ }^{37-40}$ Appointments usually include ongoing care, limited urgent care, and some preventive screenings (detail in Appendix). However, reports on the successes of DPC and concierge care are generally not published in the scientific literature nor use optimal evaluation designs. ${ }^{37,38}$

In general, studies empirically comparing slow to fast medicine in the US are sparse, lacking formal trials (global literature detail in Appendix). Review articles do not find US studies of high enough quality to contribute to formal syntheses. There are no rigorous studies with strong comparison groups on patient outcomes related specifically to consultation duration; evaluations of lengthened consultations incorporate other intervention components, making it impossible to isolate the effects of duration. Furthermore, studies are hard to generalize due to location or date. Thus, the final word on slow medicine is not in.

Our goal was to identify, review, and summarize existing reports to determine if there is enough evidence to support randomized controlled trials (RCTs) or other systematic evaluation of slow medicine. In other words, is existing evidence sufficiently suggestive of a clinical or economic benefit to warrant best practice clinical trials in the US?

\section{Methods}

"Slow medicine" has no universal defining criteria but usually includes elements of increased consultation duration and improved engagement, as well as shared decision-making with patients. ${ }^{34}$ For this review, we focused on the effect of increased faceto-face consultation duration (with or without other care enhancements) on quantified clinical process and health outcomes. We confined our scope to primary care, including CM and DPC.

We found publications that compared the effect of shorter and longer consultations on utilization (hospitalization, hospital readmission, emergency department [ED] visits, acute care use, surgeries); preventive care (service delivery, quality indicator performance, immunizations, referrals); visit performance (problems addressed, in-depth assessment, patient history scores, physical examination scores, emotional distress diagnosis, coding for chronic conditions); medication adherence and prescription volume; mortality; and cost. We omitted studies that focus solely on patient or physician satisfaction or communication.

We limited our review to the US because of our unique circumstances: complex insurance and reimbursement arrangements alongside related timeconsuming EHRs; malpractice and litigation; primary care training and practice environment; the role of specialist referrals; and attitudes, practices, and incentives regarding prescriptions, testing and screening, and interventions.

We searched PubMed and Google using the following terms and syntax: [primary care OR ambulatory care] AND [visit length $\mathrm{OR}$ consultation duration $\mathrm{OR}$ consultation length $\mathrm{OR}$ patient 
physician encounter OR time with patients OR visit time OR panel size], plus further targeting with US, intervention, and patient outcomes. We also searched using keywords contained in articles included in our review. Finally, we reviewed citations in published reports and e-mailed experts in the field.

\section{Results}

We found 11 assessments, in 3 categories, that included both information on consultation duration (quantified or implicit) and outcomes of interest: 4 case studies of the effects of concierge care ${ }^{1}$ and DPC, ${ }^{3}$ with increased consultation time and no insurance, EHR, or meaningful use constraints; 3 evaluations of increased consultation duration along with other enhancements for elders; and 4 cross-sectional evaluations of nationally representative data assessing the association between consultation duration and patient outcomes (3 precede widespread EHR use).

We consider these 11 assessments representative of a slow medicine approach either due to lack of restrictions on or lengthier consultation duration (concierge care and DPC); lengthier consultation duration, smaller patient panel size, or more frequent visits (multifaceted care models for elders); and measurement of consultation duration associated with outcomes of interest (cross-sectional evaluations).

All studies are discussed below, with more detailed numeric results presented in Table 1 (methods) and Table 2 (results), and in the Appendix. Information on methods and outcomes that are present for some but not all assessments reflect reporting inconsistencies.

\section{Assessments of Concierge Medicine and Direct Primary Care}

Use and cost data from CM and DPC studies are limited by lack of randomization and, in some instances, inadequate reporting of methods and results. Findings as reported are strongly favorable.

\section{Concierge Care: MDVIP}

MDVIP provides primary care in 45 states, individualizing preventive care guided via screening questionnaires and lab diagnostics. We found 2 evaluations.

A 2006 to 2010 study in 5 states found $49 \%$ to $72 \%$ lower utilization for elective, nonelective, emergent, urgent, avoidable, and unavoidable admissions for MDVIP members than for nonmembers insured by commercial plans, and $71 \%$ to $79 \%$ lower use than for Medicare enrollees. ${ }^{41}$ In 2009, MDVIP Medicare enrollees were readmitted less frequently than nonmembers for several conditions. Lowered use led to overall cost savings versus both commercial (\$10 million) and Medicare (\$109 million) enrollees.

The interpretation of these differences is unclear because concierge patients often differ from other patient groups due to self-selection (they may be more motivated to address health concerns or have conditions that have not been sufficiently addressed previously), and concierge physicians may practice differently than peers. Concierge patients may be healthier, and concierge physicians may be more motivated and adept at providing prevention. ${ }^{41,42}$ Demographics may also differ: a 2005 survey found fewer CM and DPC patients of color compared with a national random sample of conventional primary care patients. ${ }^{43}$

A more recent and rigorous 2009 to 2014 study compared MDVIP members and controls matched on propensity to enroll in MDVIP from the United HealthCare employer health plan database. It found significant reductions in emergency room (ER) and urgent care use and inpatient readmissions but not inpatient admissions. ${ }^{42}$ Medical and pharmacy expenditures were higher for MDVIP members in year 1 but similar by year 3 . Increasing cost savings of $\$ 150$ per member per month (pmpm; the average membership cost), was realized over 3 years. Member characteristics associated with higher savings differed by year.

As with the earlier study, self-selection cannot be entirely eliminated as an explanation, even though matching incorporated enrollment propensity scores.

\section{DPCs: Qliance, Iora, and R-Health}

Utilization assessments from DPC practices are few and challenging to assess because they are not reported in the scientific literature. Two large DPC providers, Qliance and Iora, reported reductions in costly use compared with nonDPC participants from the same population groups.

\section{Qliance}

Qliance, in the Seattle area, served employees of many large employers. ${ }^{44,45}$ Unpublished 2010 


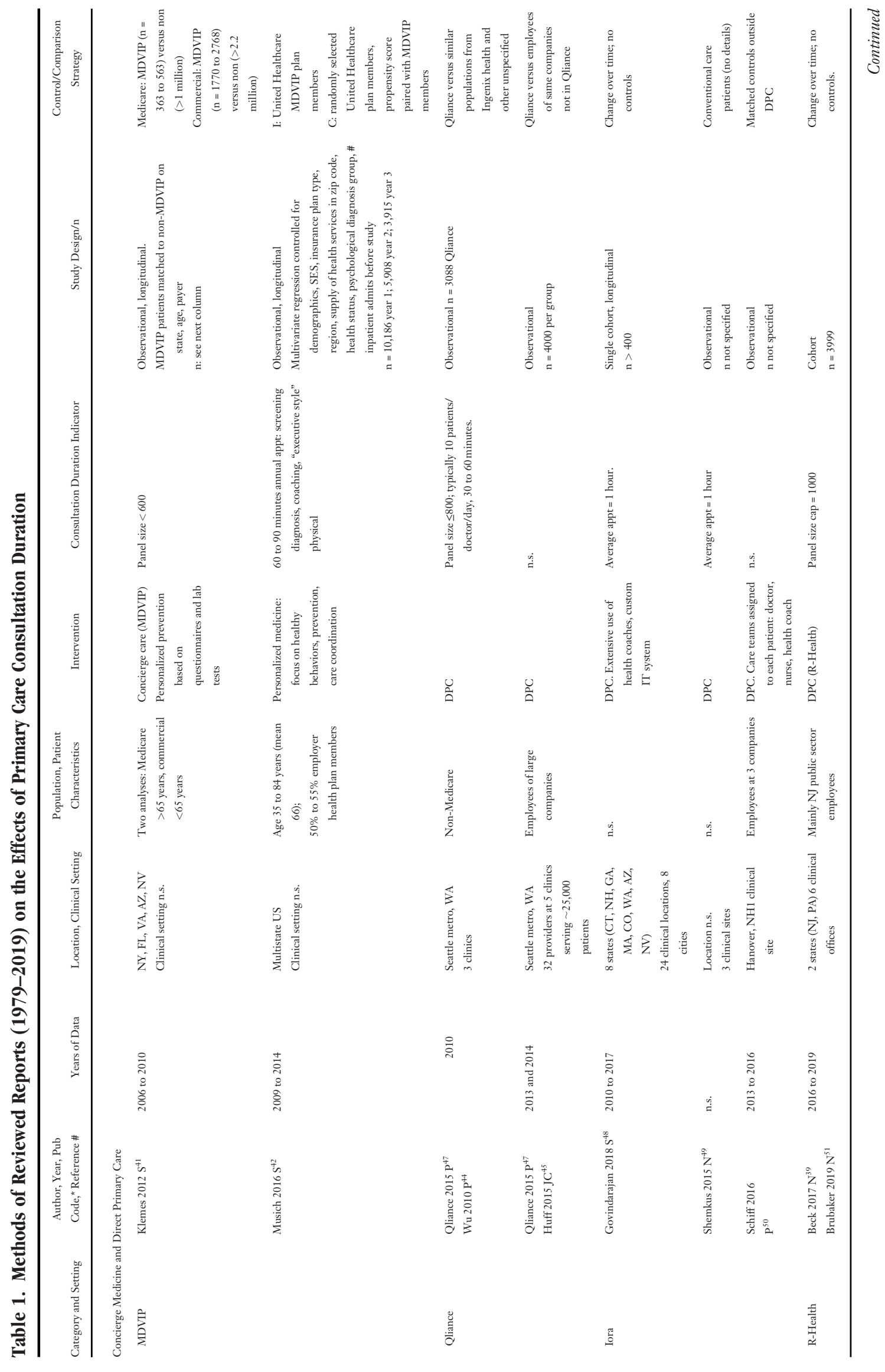

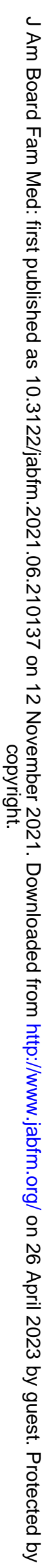



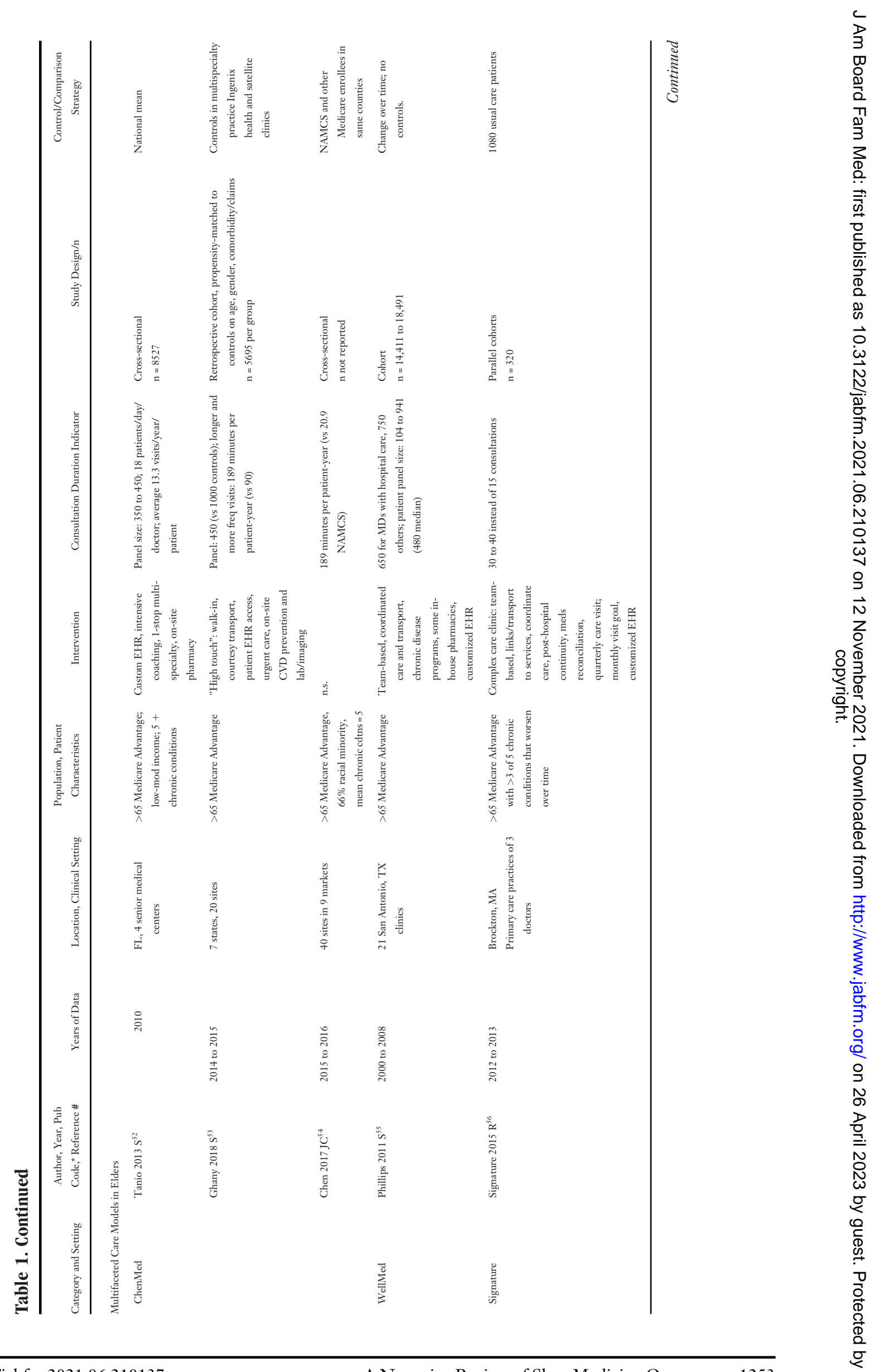


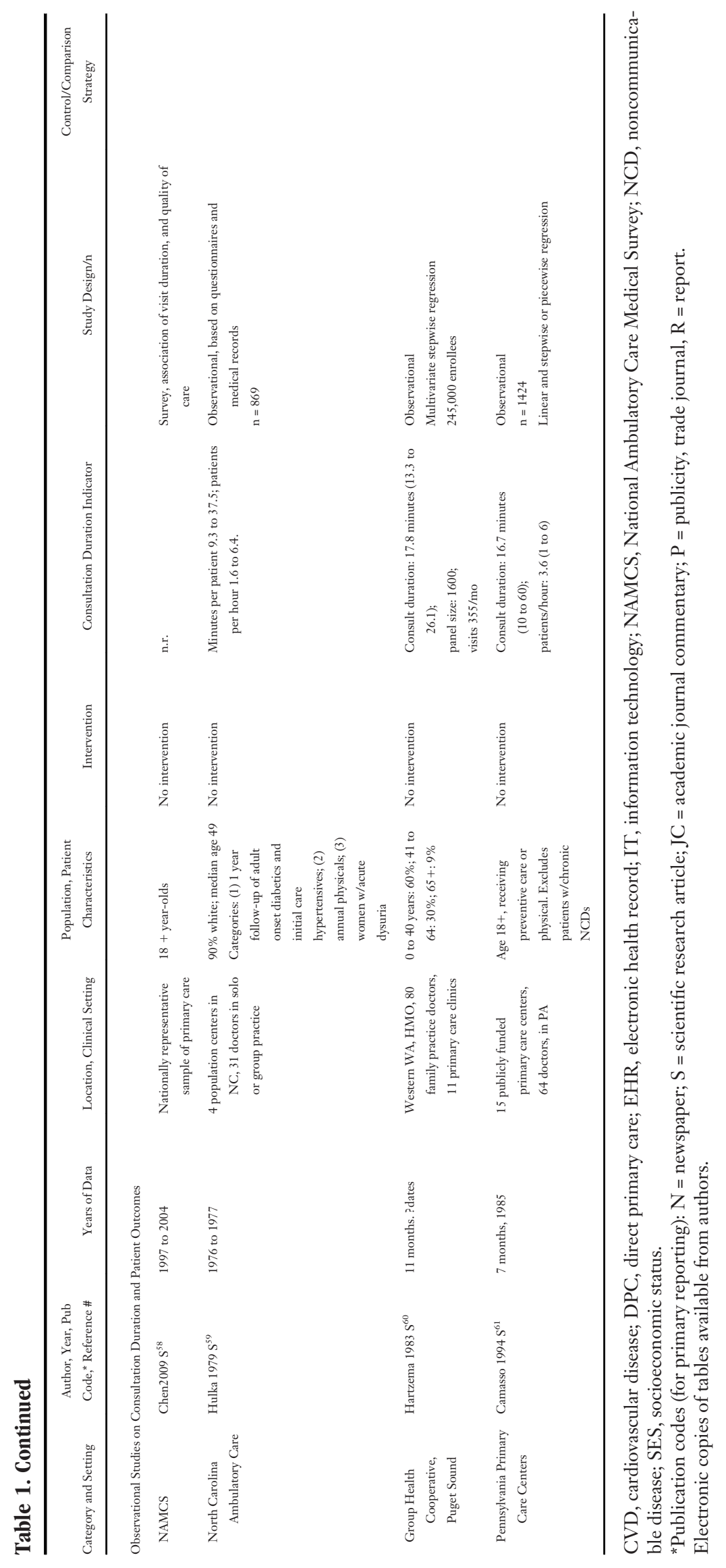




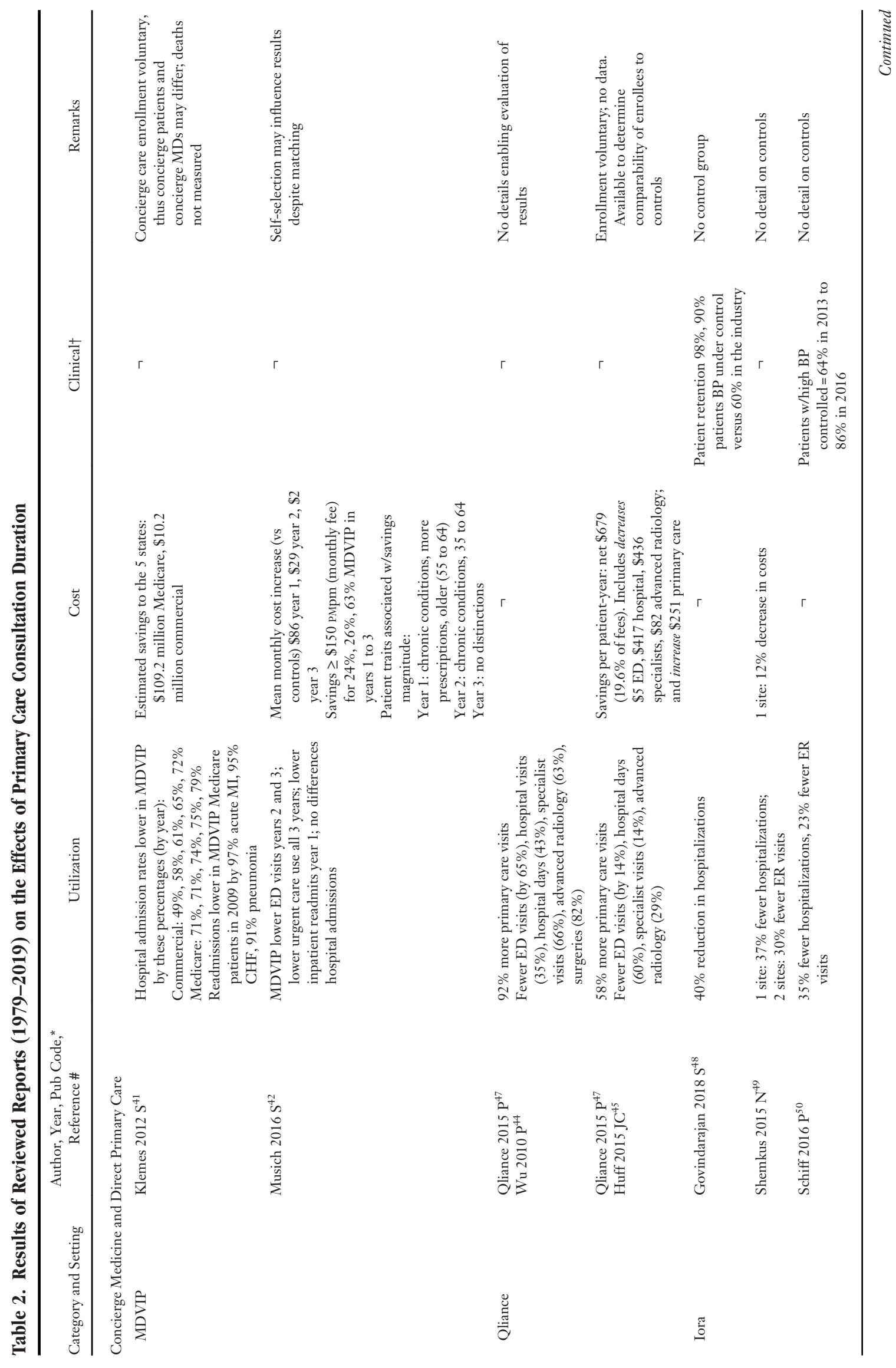




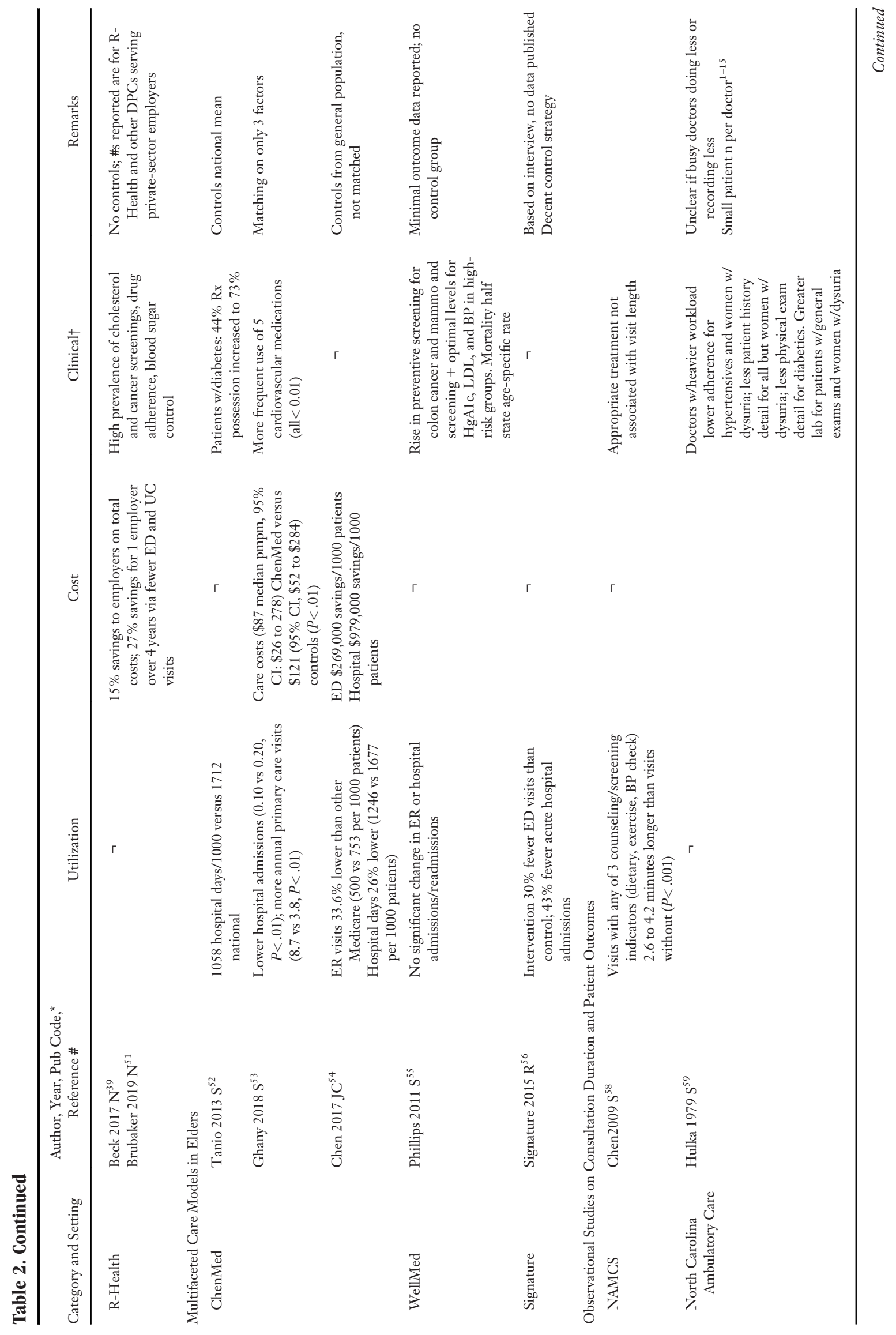




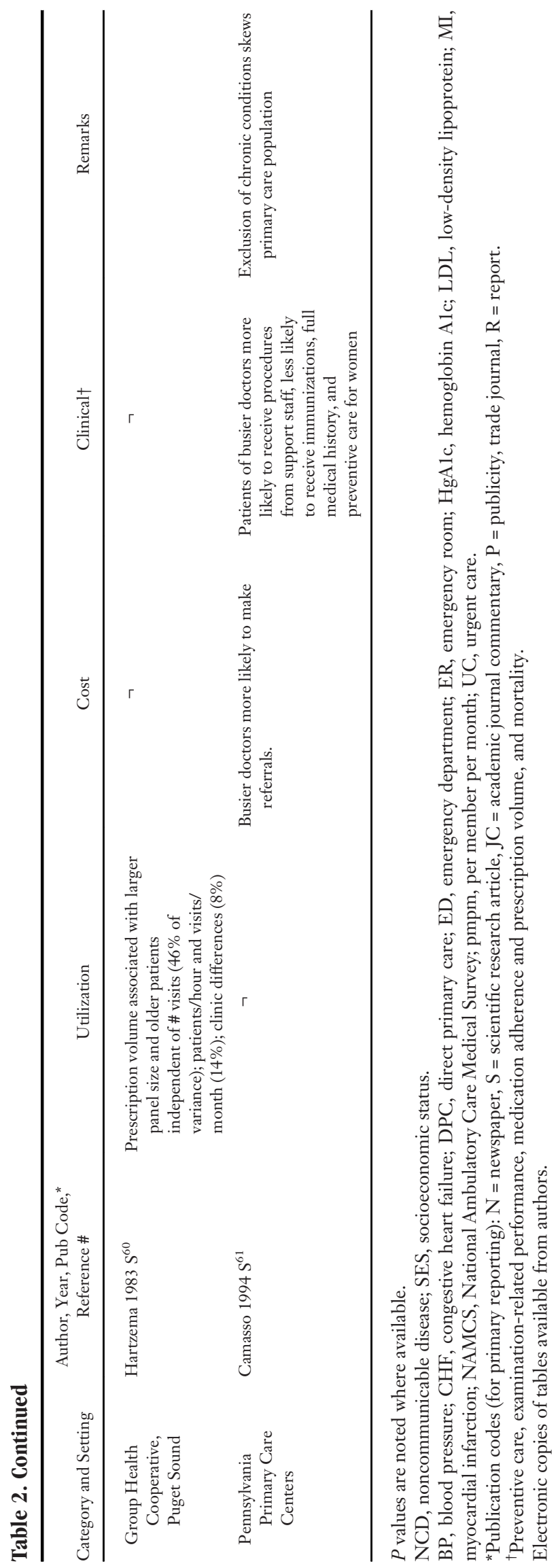


claims data for non-Medicare Qliance enrollees found considerably higher primary care use (92\%) but greatly reduced use (ranging from 35\% fewer hospitalizations to $82 \%$ fewer surgeries) compared with similar populations. ${ }^{46}$

A 2015 news release comparing 2013 and 2014 claims data for Qliance enrollees to nonenrollees working for the same companies reported similar utilization findings. ${ }^{47}$ The added cost of primary care was offset by nearly $20 \%$ savings on other types of use; annual savings per patient ranged from $\$ 5$ for $\mathrm{ED}$ visits to $\$ 436$ for specialist visits.

\section{Iora}

Iora Health, currently with 47 clinics in 9 states, reported up to $20 \%$ decreased health care spending, a $40 \%$ reduction in hospitalization, and favorable blood pressure control (90\%) compared with industry standards (60\%) between 2010 and 2017. ${ }^{48}$ Earlier Iora results found over a third lower hospitalization and just over $10 \%$ lower health care spending at 1 site and $23 \%$ to $30 \%$ fewer emergency department visits at 2 sites, compared with patients outside the practice matched on unspecified criteria. ${ }^{49,50}$ Iora primarily serves full-risk Medicare Advantage patients and is in the process of being acquired by One Medical, a concierge fee-for-service provider.

These estimates lack control groups and instead are based on patterns over time for enrollees.

\section{R-Health}

R-Health launched a pilot program for New Jersey public employees and retirees in 2016 at 6 offices, adding 4 offices serving large employers in Southeastern Pennsylvania. ${ }^{39,51}$ Ameriflex, a private-sector employer that uses R-Health and other DPCs, reported a $15 \%$ overall cost savings and high prevalence of preventive screening, medication adherence, and blood sugar control in 2017 (no numbers provided). ${ }^{39}$ Over 4 years, $27 \%$ cost savings were attributed primarily to reduced ER and urgent care use. ${ }^{51}$ The absence of details precludes commenting on the quality of RHealth evaluations.

\section{Assessments of Multifaceted Care Models in Elders}

Three health care organizations assessed the effects of a more comprehensive service delivery model for Medicare Advantage enrollees. Two of the 3 explicitly noted longer consultation duration (ChenMed and Signature), 2 had smaller patient panel sizes (ChenMed and WellMed), and 2 had more frequent visits (ChenMed and Signature). All 3 included additional enhancements and all reported improvements in patient outcomes. However, the contribution of consultation duration cannot be isolated from other intervention elements.

\section{ChenMed}

Dr. James Chen founded ChenMed in Miami in 1985 after his experience as a cancer patient, adopting a "high intensity primary care" approach. Smaller patient panel size, a prevention emphasis, in-house multispecialty and pharmacy services, and other enhancements characterize the clinics. A 2010 evaluation of 4 Miami-area health centers found a two-thirds decrease in hospital days among Medicare Advantage enrollees with 5 or more chronic conditions and low to moderate incomes compared with the national average, and one-third increase in medication adherence for patients with diabetes. $^{52}$

By 2014, ChenMed expanded to 7 states. A propensity-matched 2014-15 comparison for clinically high-risk primary care patients at more than 20 offices to those at a value-based multispecialty practice and its satellite clinics found \$34 lower monthly health care costs, lower hospital admissions, more annual primary care visits, and more frequent use of 5 cardiovascular medications. ${ }^{53}$

In 2015-16, ChenMed had 40 locations in 9 US markets. ${ }^{54}$ ChenMed patients had a third fewer ER visits than Medicare beneficiaries in the same counties and a quarter fewer hospital days that together yielded savings of $\$ 1.2$ million per 1000 patients.

Although ChenMed patient populations seem high risk, potential bias due to self-selection for enrollment remains an important consideration. It is unclear which of many factors, including longer consultation duration, contribute to the observed differences.

\section{WellMed}

WellMed, an accountable care organization (ACO), evaluated 21 San Antonio clinics with small patient panel size, team-based care, chronic disease programs, in-house pharmacies at many sites, coordinated care and transportation, and a customized EHR, among other enhancements. ${ }^{55}$ Billing and EHR data from 2000 to 2008 found no significant differences in use for ED visits, hospitalization, or 
hospital readmission. Increases in 12 clinical process measures (including colon cancer screening and mammography) and screening and optimal levels of $\mathrm{HbA1c}, \mathrm{LDL}$, and blood pressure for patients in specific high-risk groups, were reported. Mortality rates were half of age-specific rates for Texas peers.

It is unclear which aspects of the care model contributed to observed clinical improvements, nor is it possible to control for self-selection bias.

\section{Signature Healthcare}

In 2013, Signature Healthcare implemented a complex care clinic in Brockton, MA for 320 frail elders with managed Medicare. ${ }^{56,57}$ The team-based coordinated care model included links to community services, routine risk screening, posthospital discharge follow-up, medication reconciliation for patients at high risk of interactions, home visits, and an EHR template to identify geriatric issues. Patients were seen quarterly to monthly in primary care, and visit slots were increased from 15 to between 30 and 40 minutes.

Claims data for all high-risk elders were compared with patients receiving usual care the year before versus after complex care clinic implementation. The intervention group had a third fewer ED visits and just over $40 \%$ decreased acute admissions, whereas usual care patients had increased ED use and no change in acute admissions.

While in keeping with the 2 other studies with elders, the description of this intervention is difficult to evaluate as it is based on an interview (not a published report) and general descriptions of the intervention. The comparability of the intervention and control groups is unclear.

\section{Observational Cross-Sectional Studies}

Four observational studies in usual care settings, ${ }^{58-61}$ including 3 before widespread EHR use, ${ }^{59-61}$ assessed the association of visit duration and clinical process outcomes. Changes in medical care structure, incentives, and information technology (IT) demands since these studies were conducted are considerable and should be considered when interpreting the results. All of these studies lack comparison groups but otherwise use rigorous methods, and all but $1^{59}$ use multivariate analytics.

\section{National Sample}

A retrospective analysis of a nationally representative sample of general primary care medical exams between 1997 and 2004 from the National
Ambulatory Care Medical Survey (NAMCS) found no association between appropriate prescribing practices and visit length. ${ }^{58}$ However, all 3 counseling or screening indicators (dietary, exercise, blood pressure check) were significantly associated with longer visits; visits where any of the 3 counseling or screening indicators were provided were 2.6 to 4.2 minutes longer than visits for patients who did not receive these interventions.

\section{North Carolina}

A study conducted in 1976 and 1977 in 4 major North Carolina population centers examined adherence to physician-defined consensus criteria on history taking, physical examination, and lab and other procedure ordering and recording among 31 randomly sampled ambulatory care physicians in solo and group practices. ${ }^{59}$ Authors hypothesized an inverse relationship between workload and consensus criteria adherence.

Physicians with heavier workloads were significantly less likely to adhere to consensus criteria for hypertensives and women with dysuria; record patient history details (except for women with dysuria); and record physical examination details for patients with diabetes. However, physicians with heavier workloads were more likely to obtain and record lab and other procedure data for patients receiving general exams and for women with dysuria. The authors estimated that half the observed differences were real and not due to recording differences.

\section{Western Washington}

An 11-month retrospective study published in 1983 examined physician and patient characteristics associated with prescribing patterns for 80 family practice physicians at 111 primary care clinics with the Group Health Cooperative of Puget Sound in Western Washington. ${ }^{60}$ Based on stepwise multivariate regression, independent of number of visits, physicians with larger panels wrote more prescriptions (explaining 23\% of the variance). Older panel age, number of patients seen per hour and visits per month, and interclinic differences were also independently predictive of prescribing patterns.

\section{Pennsylvania}

A 1985 medical record review at 15 publicly funded Pennsylvania primary care centers evaluated the association between patient volume and preventive 
and well care delivery. ${ }^{61}$ Busier physicians made more referrals, were significantly more likely to delegate certain procedures to support staff, and significantly less often provided immunizations and preventive care for women or elicited risk behaviors and medical history. Both less busy and busier physicians conducted fewer blood count procedures.

\section{Discussion}

Evidence we located suggests that in the United States, increased primary care consultation duration may foster improved clinical processes and patient outcomes and reduce use of expensive emergency and inpatient services. Interventions increasing consultation duration often result in greater primary care costs, but these were more than offset by decreased inpatient, ED, and specialist use. ${ }^{46,47,53}$

However, the data are not robust. Participants in settings with longer consultation duration are usually self-selected and thus potentially different in their health care habits. Patients may enter programs targeting high-risk patients due to frequent inpatient use and then regress to the mean (eg, as with diabetes), ${ }^{62}$ creating a false impression of beneficial effects of care. Further, consultation duration is usually bundled with other care delivery enhancements, making its effects impossible to isolate. Finally, data disseminated in news or marketing channels sharply reduces scientific credibility. While we may believe that longer consultations should yield improved care and outcomes, and as suggestive as findings may be, the extant US data are inconclusive.

Nevertheless, the potential clinical and economic gains of slow medicine are substantial. We believe it is time to conduct high-quality clinical research (ie, well-done RCTs, natural experiments, and mixed-methods studies employing qualitative and quantitative approaches) on the effect of consultation duration on preventive care, visit elements, medication adherence and prescription volume, and mortality as outcomes of interest in addition to utilization and cost. Measures of physician and patient experience and satisfaction should be included in further studies. Time spent face-toface by physicians with patients should be differentiated from EHR tasks, follow-up, administrative time, and so forth, using techniques such as observation and EHR logs that have set the standard in the literature.
We need definitive evidence to inform such substantial changes in the organization of care. Criteria for a clinical trial are met: we have a plausibly superior intervention and are in equipoise. Adding time will not place study participants at risk; to the contrary, they, along with physicians, will likely perceive the added time favorably and may realize clinical benefit. Randomization could occur at different levels, each with advantages and limitations: the clinical unit, the provider, or the patient.

Fast medicine primary care settings with longer consultation duration are worthy of study. These may include settings where physician practice style overrides pressures to restrict time with patients, teaching hospitals that assign physician researchers smaller patient panel sizes, practitioners who more fully capture diagnoses through RVU coding and thus gain time, organizations with different demands and constraints such as the Veteran's Administration, and rural settings where family physicians in individual practice still conduct house calls.

Natural experiments also have potential because they take advantage of factors beyond investigator control that create a natural randomization (eg, policy or budget decisions that start or stop programs). The best opportunity for a natural experiment we know of is the geographic staging of the DPC R-Health in New Jersey and Strada in Nebraska. The stepwise phasing in of R-Health and Strada should permit comparison of utilization in initial and delayed areas. As DPCs, they are not involved with insurance company reimbursement requirements and thus are not subject to limitations on consultation duration.

Large-scale demonstration projects may eventually have a role. If high-quality evidence at small scale confirms benefits, the next area of inquiry will be the feasibility and effects of implementation in larger patient populations, such as entire health systems in a metropolitan area.

High-quality clinical encounter data will facilitate research using any of these designs. Current clinical data reporting is piecemeal, available by health care provider and, in different form, by insurer. Enhancing existing efforts to combine claims databases would improve clinical data uniformity, quality, and timeliness. A unified health insurance system, such as single payer, would provide excellent data and might also facilitate compensation 
structure adjustments necessary to foster longer consultation duration. ${ }^{63}$

In the absence of a unified health insurance system, efforts to pool and share encrypted longitudinal patient data to evaluate patient and physician experience and outcomes when the constraints of time, EHR burden, and administrative red tape are lessened would be beneficial.

Incorporation of longer consultations into routine clinical practice may require substantial adjustments to scheduling and per-visit reimbursements or capitation rates. Longer consultations in the absence of other changes will necessitate longer intervals between patient visits and/or greater use of nonphysician providers. If $25 \%$ of consultations are doubled in length, total consultation time will increase $25 \%$. EHR burden may not be alleviated with slow medicine; time for EHR tasks may increase due to longer face-to-face time with patients. If longer consultations are accompanied by other changes, such as simplified EHR obligations, the changes may have offsetting effects on scheduling and payment needs. Further inquiry should identify operational efficiencies and optimal panel sizes necessary for implementation of longer consultation duration, especially in light of primary care workforce shortages. On the other hand, the ability to spend sufficient time with patients may attract medical students to primary care. Although we do not underestimate the challenges of making such adjustments, we believe that practical issues should follow on and reflect clinical trial results, not preclude those trials.

\section{Limitations}

Our ability to identify all relevant articles was hampered by the broad literature that encompasses consultation duration; we may have missed studies that focus on other issues. As noted, we could not isolate consultation duration from other practice features (ie, consultation duration may be a marker for physician attributes) (details in Appendix). The nature of the publications is often compromised by inadequate methods specification and limited data presentation. In addition, many of the studies precede the current environment and demands of primary care. They all precede the COVID-19 pandemic, with its disruption of routine medical practice. The inadequacy of the data reinforces the need for controlled trials.

\section{Conclusions}

We believe that high-quality research is both timely and necessary to better understand the effects of consultation duration on patient and physician experience, patient outcomes, utilization, and costs. Randomized studies in diverse primary care populations that isolate the effects of longer consultations could advance more effective and efficient patient care. Natural experiments, such as the DPC options offered on a population level to New Jersey public employees (R-Health) and in Nebraska (Strada), present rich opportunities for such evaluations. Given the extent of patient unhappiness and primary care physician burnout, as well as the high prevalence of overtreatment, such investigations may help restore some of primary care's full potential.

To see this article online, please go to: http://jabfm.org/content/ 34/6/1249.full.

\section{References}

1. Sinsky C, Colligan L, Li L, et al. Allocation of physician time in ambulatory practice: a time and motion study in 4 specialties. Ann Intern Med 2016;165:753-60. Available from: https://www. acpjournals.org/doi/10.7326/M16-0961?url_ver= Z39.88-2003\&rfr_id=ori:rid:crossref.org\&rfr_dat= cr_pub\%20\%200pubmed. Accessed January 6, 2021.

2. Arndt BG, Beasley JW, Watkinson MD, et al. Tethered to the EHR: primary care physician workload assessment using EHR event $\log$ data and time-motion observations. Ann Fam Med 2017;15:419-26. Available from: https://www.ncbi. nlm.nih.gov/pmc/articles/PMC5593724/. Accessed January 6, 2021.

3. Hunt LM, Bell HS, Baker AM, Howard HA. Electronic health records and the disappearing patient. Med Anthropol Q 2017;31:403-21. Available from: https://www.ncbi.nlm.nih.gov/ pmc/articles/PMC6104392/. Accessed February 1, 2021.

4. Bradley EH, Elkins BR, Herrin J, et al. Health and social services expenditures: associations with health outcomes. BMJ Qual Saf 2011;20:826-31. Available from: https://qualitysafety.bmj.com/ content/20/10/826.full. Accessed January 6, 2021.

5. Bradley EHT, Taylor LA. The American health care paradox, why spending more is getting us less. New York: Public Affairs, 2013.

6. Kaufman SR. Ordinary medicine: extraordinary treatments, longer lives, and where to draw the line. Durham (NC): Duke University Press, 2015.

7. Brownlee S. Overtreated — why too much Medicine is making us sicker and poorer. New York: Bloomsbury, 2007. 
8. Linzer M, Bitton A, Tu SP, Association of Chiefs and Leaders in General Internal Medicine (ACLGIM) Writing Group, et al. The end of the 15-20 minute primary care visit. J Gen Intern Med 2015;30:1584-6. Available from: https://www.ncbi.nlm.nih.gov/pmc/ articles/PMC4617939/. Accessed January 7, 2021.

9. Upshur RE. Do clinical guidelines still make sense? No. Ann Fam Med 2014;12:202-3. Available from: http://www.annfammed.org/content/12/3/202.full. Accessed January 7, 2021.

10. Bodenheimer T. Primary care-will it survive? N Engl J Med 2006;355:861-4. Available from: https:// www.nejm.org/doi/10.1056/NEJMp068155. Accessed January 11, 2021.

11. Wachter RM. The digital doctor: hope, hype, and harm at the dawn of medicine's computer age. New York: McGraw Hill, 2015.

12. Downing NL, Bates DW, Longhurst CA. Physician burnout in the electronic health record era: are we ignoring the real cause? Ann Intern Med 2018;169:50-1. Available from: https:// annals.org/aim/article-abstract/2680726/physicianburnout-electronic-health-record-era-we-ignoringreal-cause. Accessed January 7, 2021.

13. Sinsky CA, Privitera MR. Creating a "manageable cockpit" for clinicians: a shared responsibility. JAMA Intern Med 2018;178:741-2. Available from: https://jamanetwork.com/journals/jamainternal medicine/article-abstract/2674872. Accessed January 28, 2021.

14. Tai-Seale M, Olson CW, Li J, et al. Electronic health record logs indicate that physicians split time evenly between seeing patients and desktop medicine. Health Aff (Millwood) 2017;36:655-62. Available from: https://www.ncbi.nlm.nih.gov/ pmc/articles/PMC5546411/. Accessed February 9, 2021.

15. Verghese A. Culture shock-patient as icon, icon as patient. N Engl J Med 2008;359:274851. Available from: http://www.nejm.org/doi/ full/10.1056/NEJMp0807461\#t=article. Accessed January 8, 2021.

16. Welch HG, Schwartz LM, Woloshin S. Overdiagnosed: making people sick in the pursuit of health. Boston (MA): Beacon Press, 2012.

17. $\mathrm{Hg}$ W. Less medicine, more health; 7 assumptions that drive too much medical care. Boston (MA): Beacon Press, 2015.

18. Robert Wood Johnson Foundation. 2011 physicians' daily life report. November 15, 2011. Available from: https://www.issuelab.org/resources/12550/12550.pdf. Accessed January 7, 2021.

19. Merritt Hawkins. 2018 survey of America's physicians: practice patterns and perspectives; an examination of the professional morale, practice patterns, career plans, and perspectives of today's physicians, aggregated by age, gender, primary care/specialists and practice owners/employees.
The Physicians Foundation; September 2018. Available from: https://physiciansfoundation.org/ wp-content/uploads/2018/09/physicians-surveyresults-final-2018.pdf. Accessed February 1, 2021.

20. Regina Corso Consulting. 2017 patient survey report for the Physicians Foundation. June 2017. Available from: https://physiciansfoundation.org/ wp-content/uploads/2017/12/Physicians_Foundation_ 2017_Patient_Survey_Report.pdf. Accessed January 11, 2021.

21. Gawande A. Overkill. New Yorker; May 4, 2015. Available from: https://www.newyorker. com/magazine/2015/05/11/overkill-atul-gawande. Accessed January 8, 2021.

22. Lyu H, Xu T, Brotman D, et al. Overtreatment in the United States. PLoS ONE 2017;12:e0181970. Available from: https://doi.org/10.1371/journal. pone.0181970. Accessed February 9, 2021.

23. Ghorob A, Bodenheimer T. Share the Care $^{\mathrm{TM}}$ : building teams in primary care practices. J Am Board Fam Med 2012;25:143-5. Available from: https://www.jabfm.org/content/25/2/143.long. Accessed January 12, 2021.

24. Wolfson D, Santa J, Slass L. Engaging physicians and consumers in conversations about treatment overuse and waste: a short history of the Choosing Wisely campaign. Acad Med 2014;89:990-5. Available from: https://journals.lww.com/academic medicine/Fulltext/2014/07000/Engaging_Physicians_ and_Consumers_in_Conversations.17.aspx. Accessed January 12, 2021.

25. Halpern J. From detached concern to empathy: humanizing medical practice. New York: Oxford University Press, 2001.

26. Leppin AL, Montori VM, Gionfriddo MR. Minimally disruptive medicine: a pragmatically comprehensive model for delivering care to patients with multiple chronic conditions. Healthcare (Basel) 2015;3:50-63. Available from: https://www.mdpi. com/2227-9032/3/1/50/htm. Accessed January 12, 2021.

27. Wen LS, Kosowsky JM. When doctors don't listen: how to avoid misdiagnoses and unnecessary tests. New York: Thomas Dunne Books/St. Martin's Press, 2013.

28. Verghese A. The importance of being. Health Aff (Millwood) 2016;35:1924-7.Oct 1. Available from: https://www.healthaffairs.org/doi/10.1377/hlthaff. 2016.0837?url_ver=Z39.88-2003\&rfr_id=ori:rid: crossref.org\&rfr_dat=cr_pub\% 20\%200pubmed. Accessed February 2, 2021.

29. Panagioti M, Panagopoulou E, Bower P, et al. Controlled interventions to reduce burnout in physicians: a systematic review and meta-analysis. JAMA Intern Med 2017;177:195-205. Available from: https://jamanetwork.com/journals/ jamainternal 
medicine/article-abstract/2588814. Accessed February 9, 2021.

30. Dolara A. Invito ad una "slow medicine" [Invitation to "slow medicine"]. Ital Heart J Suppl 2002;3:100-1. Available from: https://pubmed. ncbi.nlm.nih.gov/11899567/. Accessed January 20, 2021.

31. Bauer JL. Slow medicine. J Altern Complement Med 2008;14:891-2. Available from: https:// pubmed.ncbi.nlm.nih.gov/18925870/. Accessed January 20, 2021.

32. Honorè $\mathrm{C}$. In praise of slowness: challenging the cult of speed. New York: HarperCollins, 2004.

33. Bonaldi A, Vernero S. Slow Medicine: un nuovo paradigma in medicina [Italy's slow medicine: a new paradigm in medicine]. Recenti Prog Med 2015;106:85-91. Available from: https://www. recentiprogressi.it/archivio/1790/articoli/19492/. Accessed January 20, 2021.

34. Lie Y. Slow medicine, an international appeal on mindful healthcare; 2017. Available from: https:// www.slowmedicine.com.br/slow-medicine-aninternational-appeal-on-mindful-healthcare/ (slowmedicine Brazil website). Accessed January 20, 2021.

35. Sweet V. God's hotel: a doctor, a hospital and a pilgrimage to the heart of medicine. New York: Riverhead Books, 2012.

36. Sweet V. Slow medicine: the way to healing. New York: Riverhead Books, 2017.

37. Eskew PM, Klink K. Direct primary care: practice distribution and cost across the nation. J Am Board Fam Med 2015;28:793-801. Available from: https:// www.jabfm.org/content/28/6/793.long. Accessed January 20, 2021.

38. Eskew P. In defense of direct primary care. Fam Pract Manag 2016;23:12-4. Available from: https://www.aafp.org/fpm/2016/0900/p12.html. Accessed January 20, 2021.

39. Beck M. With direct primary care it's just doctor and patient; February 27, 2017. Available from: https://www.wsj.com/articles/with-direct-primarycare-its-just-doctor-and-patient-1488164702. Accessed January 20, 2021.

40. Rowe K, Rowe W, Umbehr J, Dong F, Ablah E. Direct primary care in 2015: a survey with selected comparisons to 2005 survey data. Kans J Med 2017;10:3-6. Available from: https:/www.ncbi. nlm.nih.gov/pmc/articles/PMC5733409/. Accessed January 20, 2021.

41. Klemes A, Seligmann RE, Allen L, Kubica MA, Warth K, Kaminetsky B. Personalized preventive care leads to significant reductions in hospital utilization. Am J Manag Care 2012;18:e453-60. Available from: https://www.ajmc.com/view/personalizedpreventive-care-leads-to-significant-reductions-inhospital-utilization. Accessed January 20, 2021.
42. Musich S, Wang S, Hawkins K, Klemes A. The impact of personalized preventive care on health care quality, utilization, and expenditures. Popul Health Manag 2016;19:389-97. Available from: https://www.ncbi.nlm.nih.gov/pmc/articles/PMC 5296930/. Accessed January 22, 2021.

43. Alexander GC, Kurlander J, Wynia MK. Physicians in retainer ("concierge") practice: a national survey of physician, patient, and practice characteristics. J Gen Intern Med 2005;20:107983. Available from: https://www.ncbi.nlm.nih.gov/ pmc/articles/PMC1490281/. Accessed January 22, 2021.

44. Wu WN, Bliss G, Bliss EB, Green LA. Practice profile. A direct primary care medical home: the Qliance experience. Health Aff (Millwood) 2010;29:959-62. Available from: https://www.healthaffairs.org/doi/ full/10.1377/hlthaff.2010.0047 ? cited-by=yes\&. Accessed January 22, 2021.

45. Huff C. Direct primary care: concierge care for the masses. Health Aff (Millwood) 2015;34: 2016-9. Available from: https://www.health affairs.org/doi/full/10.1377/hlthaff.2015.1281. Accessed January 22, 2021.

46. Qliance Medical Group. Online table; 2010. Available from: https://b-i.forbesimg.com/ davechase/files/2013/07/DPC-Qliance-reductionin-downstream-care.jpg. Accessed January 22, 2021.

47. Qliance. New primary care model delivers 20 percent lower overall healthcare costs, increases patient satisfaction and delivers better care; January 15, 2015. Available from: http://www. prnewswire.com/news-releases/new-primary-caremodel-delivers-20-percent-lower-overall-healthcarecosts-increases-patient-satisfaction-and-delivers-bettercare-300021116.html. Accessed January 22, 2021.

48. Govindarajan V, Ramamurti R. Transforming health care from the ground up. Harvard Business Review Magazine July-Aug 2018. Available from: https:/hbr.org/2018/07/transforming-health-carefrom-the-ground-up. Accessed January 22, 2021.

49. Shemkus S. Iora Health's promise: patients come first. Boston Globe May 4, 2015. Available from: https://www.bostonglobe.com/business/2015/05/ 03/iora-health-pioneers-new-primary-care-model/ kc7V4W5V8OJ0gxFqY4zBrK/story.html. Accessed January 22, 2021.

50. Schiff J. Best practices: from the bottom up, Iora Health helps providers build ACO framework. Modern Healthcare June 18, 2016. Available from: https://www.modernhealthcare.com/article/20160618/ MAGAZINE/306189997/iora-health-helpingproviders-invert-aco-models. Accessed January 22, 2021.

51. Brubaker H. This Elkins Park Company has a plan to reduce employees' health-care costs. Philadelphia Inquirer January 28, 2019. Available 
from: https://www.philly.com/business/direct-primarycare-r-health-pareto-captive-philadelphia-newjersey-20190128.html. Accessed January 22, 2021.

52. Tanio C, Chen C. Innovations at Miami practice show promise for treating high-risk Medicare patients. Health Aff (Millwood) 2013;32:1078-82. Available from: https://www.healthaffairs.org/doi/ pdf/10.1377/hlthaff.2012.0201. Accessed January 22, 2021.

53. Ghany R, Tamariz L, Chen G, et al. High-touch care leads to better outcomes and lower costs in a senior population. Am J Manag Care 2018;Sep 124:e300-e304. Available from: https://www.ajmc. com/view/hightouch-care-leads-to-better-outcomesand-lower-costs-in-a-senior-population. Accessed January 22, 2021.

54. Chen C. How concierge care for low-income seniors can improve outcomes and reduce costs. Am J Manag Care; September 25, 2017. Available from: https://www.ajmc.com/view/how-conciergecare-for-low-income-seniors-can-improve-outcomesand-reduce-costs. Accessed April 28, 2021.

55. Phillips RL, Jr, Bronnikov S, Petterson S, et al. Case study of a primary care-based accountable care system approach to medical home transformation. J Ambul Care Manage 2011;34:67-77. Available from: https://journals.lww.com/ambulatory caremanagement/Abstract/2011/01000/Case_Study_ of_a_Primary_Care_Based_Accountable.9.aspx. Accessed January 22, 2021.

56. Institute for Healthcare Improvement. Signature Healthcare: a triple aim improvement story. Cambridge, MA: Institute for Healthcare Improvement; October 2015. Available from: http:/www.ihi.org/resources/Pages/ Publications/SignatureHealthcare'TripleAim.aspx. Accessed January 22, 2021.

57. Whittington JW, Nolan K, Lewis N, Torres T. Pursuing the triple aim: the first 7 years. Milbank Q 2015;93:263-300. Available from: https://www.
ncbi.nlm.nih.gov/pmc/articles/PMC4462878/. Accessed January 22, 2021.

58. Chen LM, Farwell WR, Jha AK. Primary care visit duration and quality: does good care take longer? Arch Intern Med 2009;169:1866-72. Available from: https://jamanetwork.com/journals/jamainternal medicine/fullarticle/1108557. Accessed January 28, 2021.

59. Hulka BS, Romm FJ, Parkerson GR, Jr, Russell IT, Clapp NE, Johnson FS. Peer review in ambulatory care: use of explicit criteria and implicit judgments. Med Care 1979;17:1-73. Available from: https://www.ncbi.nlm.nih.gov/pubmed/763009. Accessed January 28, 2021.

60. Hartzema AG, Christensen DB. Nonmedical factors associated with the prescribing volume among family practitioners in an HMO. Med Care 1983; 21:990-1000. Available from: https://journals.lww. com/lww-medicalcare/Abstract/1983/10000/Non medical_Factors_Associated_With_the_Prescribing.5. aspx. Accessed January 28, 2021.

61. Camasso MJ, Camasso AE. Practitioner productivity and the product content of medical care in publicly supported health centers. Soc Sci Med 1994;38:73348. Available from: https://www.sciencedirect.com/ science/article/abs/pii/0277953694904642. Accessed January 28, 2021.

62. Schmidt MI, Bracco P, Canhada S, et al. Regression to the mean contributes to the apparent improvement in glycemia 3.8 years after screening: the ELSA-Brasil Study. Diabetes Care 2021;44:81-8. Available from: https://care.diabetes journals.org/content/44/1/81.long. Accessed July 1, 2021.

63. Marx R, Kahn JG. A perk of Medicare for all: more time for doctors and patients. KevinMD. com; December 6, 2019. Available from: https:// www.kevinmd.com/blog/2019/12/a-perk-of-medicarefor-all-more-time-for-doctors-and-patients.html. Accessed January 28, 2021. 


\section{Appendix}

\section{Background: Impact of the Electronic Health Record on Physicians and Patients}

Physician and patient experience with health care system functioning, and the electronic health record (EHR) in particular, is unique compared with similar countries. The United States ranks last among wealthy countries with respect to physician perception of health care system functioning, according to representative surveys in 10 countries conducted by the Commonwealth Fund. ${ }^{1}$ Just $16 \%$ of US primary care physicians believe that the system works well, with only minor changes needed. US primary care physicians were fourth highest in terms of regarding the job as very or extremely stressful (43\%) and fifth regarding being somewhat or very dissatisfied with the time spent per patient.

Consultations are widely perceived as uncomfortably rushed by patients and physicians. ${ }^{2,3}$ Only $11 \%$ of 1,747 nationally representative patients aged 27 to 75 who saw the same physician at least twice in the previous year felt physicians had all the time they needed to provide the highest standards of care; ${ }^{3}$ a similar proportion (14\%) of 17,236 nationally surveyed physicians felt likewise. ${ }^{4}$ Over half (57\%) of patients who saw the same physician at least twice in the previous year strongly or somewhat agreed that physicians relied more on the computer screen and less on what the patient told them during exams, and $46 \%$ strongly or somewhat agreed that physicians spent more time looking at the computer or tablet and less time looking at them. ${ }^{3}$

The surveys in 10 countries also found the US ranked second lowest in being satisfied or very satisfied with the $\operatorname{EHR}$ (52\%, after Sweden at 37\%). ${ }^{1}$ EHRs used in the US require far more administrative and low-clinical value data than in other countries, resulting in higher burden and lower physician satisfaction, suggesting the need and opportunity for simplified EHR documentation and billing requirements. ${ }^{5}$ Only 11\% of 17,236 physicians surveyed in 2016 felt that the EHR improved patient interaction, while $60 \%$ said it detracted. ${ }^{4}$ An ethnographic study of physicians and patients in 2 specialist practices found that the EHR not only disrupts and complicates but drives the clinical consultation. $^{6}$

EHR demands reduce the amount of high-quality consultation time. According to a systematic review on duration of consultations since 1946 in 67 countries, the US has the second longest consultation duration (22 minutes), after Sweden. ${ }^{7}$ However, this longer time does not correspond with physician and patient satisfaction and is unadjusted for time physicians spend attending to the EHR during consultation. Indeed, increased duration of primary care visits in the US since 2004 tracks closely with EHR adoption, suggesting added computer, not consultation, time. $^{8}$ An evaluation of more than 31 million EHR transactions by 471 primary care physicians and more than 765,000 patients from 48 primary care departments of a community-based fee-for-service health care system from 2011 to 2014 found equal time spent face-to-face versus on desktop activities. ${ }^{9}$ Face-to-face time could include the computer and decreased over the study interval, while desktop time increased. According to EHR event logs validated by observation, from 2013 to 2016, family physicians ( $\mathrm{n}=$ 142) at an academic medical center in Wisconsin devoted just under half of their workday (4.5 hours or $45 \%$ ) to the EHR, with the remainder on direct patient care, team interactions and meetings, paperwork, e-mail, and other tasks. Physicians spent a further 1.4 hours daily outside clinic hours on the EHR. ${ }^{10}$ This is similar to data gathered in 2015 from 57 physicians in 16 practices (including primary care, cardiology, and orthopedics) in 4 states that found physician time was spent $53 \%$ face-to-face with patients, $37 \%$ on the EHR and desk work, and $9 \%$ on administrative tasks. ${ }^{11}$ Thus, only 12 minutes were spent talking with and examining patients. A 2018 survey of 8774 physicians reported spending $23 \%$ of work hours on nonclinical paperwork. ${ }^{12}$ A study of 32 primary care and specialty physicians and 217 of their patients found that greater keyboard activity and gazing at the computer was significantly associated with less active patient participation and greater silence, respectively. 13

Lack of sufficient time for physicians and patients and the demands placed on physicians by the EHR have contributed to physician burnout. The physician burnout crisis is long simmering and severe; in 2018 over three quarters (78\%) of 8774 physicians surveyed nationally experienced burnout. ${ }^{12}$ Increasing demands coupled with low compensation have led to a dangerously large primary care workforce deficit. ${ }^{14,15}$ As a result, many physicians plan to reduce hours or change careers. 12,16

\section{Background: Limited Consultation Duration-Causes, Tools, and Resources}

Numerous authors call attention to the erosion of time for clinical consultation, identify causes, and suggest tools and resources to mitigate the repercussions. Proposed solutions range widely and include technological and practical innovations (eg, scribes in and outside the examination room); ${ }^{17}$ organizational and management strategies (eg, team-based care and care delegation); ${ }^{18-20}$ judicious use of evidence-based diagnostic tests and interventions including joint patientphysician decision-making (eg, Choosing Wisely, Hochmann \& Cohen's Updates in Slow Medicine blog, Lancet's 2017 Right Care Series); ${ }^{21-27}$ training to enhance communication and empathy with patients (eg, Balint Society, Narrative Medicine); ${ }^{28,29}$ and decreasing patient treatment burden (eg, Minimally Disruptive Medicine); ${ }^{30}$ patient support and empowerment via resources and tools; ${ }^{3,32}$ teaching and reclaiming the art of careful physical examination and diagnosis (eg, the Society to Improve Diagnosis in Medicine's journal Diagnosis, Stanford Medicine 25 website); ${ }^{33-35}$ physician and practice support (eg, techniques to mitigate physician burnout and reclaim 
joy in practice) $;^{19,36,37}$ and restoring physicians' ability to practice contemplatively and communicate meaningfully with patients. ${ }^{32,38,39}$

Victoria Sweet recently popularized the concept of slow medicine in the US in 2 best-selling books. ${ }^{38,40}$ She advocates sufficient time to practice contemplatively, proposing that the apparent "inefficiency" of this approach is ultimately more efficient and costeffective. She recounts cases that were misdiagnosed or mishandled due to lack of time, reflection, or listening to and laying hands on patients, over her 2 decades practicing at San Francisco's long-term care hospital, Laguna Honda, ${ }^{38}$ and during her years of training and practice. ${ }^{40}$

Some focus on specific populations: end-of-life care and elders ${ }^{41-44}$ or avoiding costly use such as rehospitalization among high-risk patients. ${ }^{45,46}$ Most clinical reforms do not involve changing the duration of consultations. Indeed, the preponderance of interventions that are formally compared with current practice emphasizes working within the current insurance-driven model of care. In this model electronic coding and billing demands of the EHR result in physicians having little control over how much time is spent interacting with patients.

\section{Background: Concierge and Direct Primary Care Practices}

Concierge practices tend to have higher monthly fees and may also bill insurance for covered services; direct primary care (DPC) practices typically charge less and do not seek insurer reimbursement; they frequently serve uninsured patients and those with high deductible plans. ${ }^{47,48}$ As DPC has expanded, average monthly fees have declined, and patient panel sizes have increased. $^{49}$ As of the beginning of 2021, there were 1423 DPC practices in 48 states and Washington, D.C. ${ }^{50}$ A 2015 study of publicly available data on 116 DPC practices found average monthly patient fees were $\$ 93$ (median $\$ 75$; range: $\$ 27$ to $\$ 563) .{ }^{51}$ A 2018 survey reported DPC monthly fees averaged $\$ 50$ to $\$ 75$ for individuals and up to $\$ 175$ for families, with mean panel size of 345 patients and target panel size $600 .{ }^{52}$ While added provider time increases costs, concierge medicine (CM) and DPC may realize offsetting savings by reducing use of high-cost services, such as emergency, inpatient, and specialist care. ${ }^{53}$ Rapid scale-up of DPCs serving large employers ended in 2 DPCs (Qliance and a previous partner of Iora-Turntable) going out of business, perhaps due to the involvement of investors who sought rapid returns on investment,${ }^{54}$ failure to secure long-term funding, ${ }_{56}^{55}$ and the nonrenewal of 2 large employer contracts. ${ }^{56}$

\section{Background: Global Literature on Consultation Duration Evaluation}

The global literature is more extensive than the US literature and includes systematic and Cochrane reviews, but findings are inconsistent. Some studies report increased receipt of important aspects of recommended care and better outcomes with increased consultation duration, while other studies are merely suggestive or find no association. In some studies, it is not possible to distinguish whether duration is associated with patient outcomes or whether it is a marker for other physician factors. Controlled intervention trials are called for by many of the authors.

An impressive systematic review spanning 1946 to 2016 in 67 countries assessed average primary care physician consultation duration by country and its association with country-level economic and health outcomes. ${ }^{57}$ Across nations there was no association between consultation duration and specific procedures (radiograph, ultrasound, or other scan) in the past 12 months $\left(P=.86, \mathrm{R}^{2}=0.001,22\right.$ observations $)$ or $\mathrm{ED}$ use $\left(P=.75, \mathrm{R}^{2}=0.01,22\right.$ observations $)$. Countries with longer consultations had lower use as measured by hospital readmission for diabetes $(P=$ $.04, \mathrm{R}^{2}=0.27,23$ observations) but not for COPD or asthma.

Wilson and colleagues have conducted 3 systematic reviews on the outcomes of longer primary care consultations, ${ }^{58-60} 2$ of which ${ }^{58,59}$ were Cochrane reviews. The 2002 review included 10 observational studies on the effect of duration on consultation process and patient outcomes (we include the 3 US studies in our review) and concluded that it is unclear whether duration is a causal factor or if it is a marker of other physician attributes. ${ }^{60}$ Nevertheless, they find the results suggestive and state that longer consultations increase the likelihood of including important aspects of care. They concluded that long-term intervention trials including cost-benefit analyses are needed. The 2006 review assessed 4 randomized controlled trials (RCTs) and controlled clinical trials (CCTs) ${ }^{61-64}$ in the UK that altered primary care consultation duration and did not support prior observational study findings. ${ }^{59}$ The authors noted that selfselection of physicians who consult more slowly might be a marker of other attributes, or that short-term changes in duration are insufficient to alter physician behavior. The 2016 review included 5 small observational studies in the UK and found that longer consultation duration was associated with less prescribing, increased lifestyle advice and prevention, and a practice style allowing more problem-solving and greater information exchange. ${ }^{58}$ However, the authors noted that valid generic outcome measures were lacking, and that without randomization it is unclear whether duration is related to these outcomes or is a marker of other physician attributes. The authors' confidence in the studies was very low and did not support policies on consultation duration; instead, they recommended further trials assessing clinical outcomes and costeffectiveness.

Observational studies of note on consultation duration outside the US include 3 from the UK ${ }^{65-67}$ and 2 with Canadian elders. ${ }^{68,69}$ Longer consultations in these studies were associated with higher scores on quality of care for chronic disease management, ${ }^{65}$ greater attention to psychosocial and long-term health problems as well as health promotion, ${ }^{66}$ and 
fewer prescriptions and returns for follow-up. ${ }^{67}$ The 2 Canadian studies with elders found significantly more prescribing among physicians seeing more patients ${ }^{68}$ and a significant association between increased visit length and appropriate elicitation of prescription contraindications and relevant patient history. ${ }^{69}$

A robust multifaceted intervention that included increased consultation duration (as well as continuity of care, physician support, holistic patient assessments, identified patient concerns and priorities, patient self-management tools, care plans, and linkages to community services) conferred benefits in a relatively recent cluster RCT in Glasgow. ${ }^{70}$ Patients $(\mathrm{n}=152)$ aged 30 to 65 with 2 or more chronic conditions in 8 general practices had longer consultation duration in the intervention arm (30 to 45 minutes). Though utilization was not reported, negative patient well-being was significantly lower and a gain in quality-adjusted life year (QALY) of 0.076 was observed over 12 months. However, the singular contribution of time to these outcomes is unclear.

\section{Results of Additional Information on Reviewed Studies}

\section{Concierge \\ MDVIP}

Founded in 2000, MDVIP uses screening questionnaires (eg, for depression, anxiety, sleep, nutrition, sexual function, vision, and hearing) and lab diagnostics (eg, for diabetes, bone density, and cardiovascular disease) to tailor patient care. ${ }^{71,72}$ The membership fee is $\$ 125$ to $\$ 175$ per month. For the earlier study, ${ }^{71}$ comparative data were obtained from Intellimed, the US census, and Claritas, and patients were matched by state of residence, age, and thirdparty coverage.

For the later study ${ }^{72}$ MDVIP members ages 35 to 84 were matched on propensity score to a randomly selected equal number of controls, based on age, sex, insurance plan type, US region, income, supply of health services, health status, psychiatric diagnostic group score, and number of inpatient admissions before enrollment. The study population was 10,186 propensity-matched pairs: 10,186 (1-year), 5,908 (2year), and 3,915 (3-year) members and nonmembers.

\section{DPCs}

\section{Qliance}

Qliance opened 3 clinics in 2007 and by 2010 had 3000 patients; practitioner panel capacity was 800 patients with a typical day of 1030 to 60 minute visits. $^{73}$ By 2015, Qliance had expanded to 5 clinics and 25,000 employees of large employers. ${ }^{48}$ Unpublished 2010 claims for 3088 Qliance non-Medicare enrollees were compared with similar populations (based on regional benchmarks from Ingenix, United Health Group, a for-profit managed care company, and other unspecified sources). ${ }^{74}$ Qliance claims data from 2013 and 2014 compared 4000 Qliance enrollees to nonenrollees working for the same large companies such as Expedia, Comcast, and Seattle Firefighters Union. ${ }^{75}$

\section{Iora Health}

Iora Health was founded in $2010 .{ }^{76}$ Average consultation duration was 1 hour. ${ }^{77,78}$ Results, reported in the Boston Globe and Modern Healthcare, are difficult to evaluate.

\section{$R$-Health}

R-Health's pilot program primarily serves New Jersey public employees and retirees (but also includes some private sector enrollees) and grew to serve 4000; their Pennsylvania clinics serve large employers and also include private-sector enrollees. ${ }^{79}$ Pennsylvania clinics charge members a flat fee of $\$ 60$ to $\$ 80$ per month.

\section{Assessments of Multifaceted Care Models in Elders ChenMed}

The 4 Miami-area ChenMed sites are characterized by smaller physician panel sizes (350 to 450 patients; physicians see 18 patients daily), high primary care use (in 2011, patients averaged 13.3 visits per year), intensive health coaching and prevention, 1-stop multispecialty services and pharmacy, a collaborative physician culture, and a customized EHR. ${ }^{80}$ Among their 8527 Medicare Advantage enrollees with 5 or more chronic conditions and low to moderate incomes, they found $62 \%$ lower hospital days (1058 per 1000 population, vs national average of 1712) and a $32 \%$ increase in medication possession, a measure of adherence (increasing from $44 \%$ to $73 \%$ ).

The 2014-15 claims data analysis included 5695 enrollees in the 2 groups matching propensity to enroll on age, gender, and comorbidity and found significant differences including lower monthly health care costs ( $\$ 87$ median per member per month [pmpm] ChenMed vs $\$ 121 \mathrm{pmpm}$ controls); lower hospital admissions; more annual primary care visits; and more frequent use of 5 cardiovascular medications (aspirin, angiotensin-converting enzyme [ACE] inhibitors/angiotensin receptor blockers [ARBs], $\beta$ blockers, statins, diuretics). ${ }^{81}$ The authors note that the limited number of matching factors may influence the results.

Some of the differences between ChenMed and the comparison model of care noted in the 2014-15 analysis included smaller patient panel size (450 vs 1000 ), longer and more frequent patient visits (average 189 minutes face-to-face per patient annually vs 90 minutes), walk-in hours, a preventive cardiovascular program on-site, and courtesy transportation. The comparison sites differed from ChenMed in permitting patient EHR access, providing on-site urgent care, and on-site lab and imaging services.

In 2015-16, ChenMed patients were described as diverse (66\% racial minorities), older, full risk, and chronically ill (average chronic conditions $=5$ ). ${ }^{82}$ Enrollees had longer average annual face-to-face 
consultation time (189 minutes per patient) than the national average (20.9 minutes according to the National Ambulatory Care Medical Survey [NAMCS]). Use was lower for ChenMed patients: $33.6 \%$ fewer emergency room (ER) visits than Medicare beneficiaries in counties served by ChenMed (500/1000 vs $753 / 1000)$ and $25.7 \%$ fewer hospital days (1246/1000 vs 1677/1000). Based on cost data from an American Hospital Association survey, the authors estimated a savings in 2015 of $\$ 268,686$ per 1000 patients due to fewer emergency department visits and $\$ 978,801$ per 1000 patients for inpatient hospitalization. Extrapolating further to a 5-physician value-based practice with 450 patients per physician panel, a practice savings of $\$ 600,000$ and $\$ 2.2$ million per year was estimated due to decreased ER and hospital use.

\section{WellMed}

WellMed was founded in 1990 and in 2011 served more than 87,000 primarily Medicare-eligible seniors in 4 states (Texas, Arkansas, Florida, and New Mexico). ${ }^{83}$ Patient panel sizes are 650 patients for physicians providing hospital care and 750 for those who do not; median panel size is 480 (range: 104 to 941). In addition to team-based care, chronic disease programs, in-house pharmacies at many sites, coordinated care and transportation, and a customized EHR, the clinics have multiple on-site services including case managers and health coaches; direct or phone access to social services; specialty care (in rheumatology, dermatology, podiatry); dental, vision, and hearing aid benefits; nutrition counseling; supervised walking programs; and hospitalists, inpatient care management teams, and nursing home nurse practitioners (NPs). Evaluation was based on 2000 to 2008 billing and 2002 to 2008 EHRs for 14,411 to 18,491 patients over the study duration.

\section{Signature Healthcare}

Signature Healthcare owns a 245-bed hospital and provides primary and specialty care for 10,000 elders in Brockton, MA. ${ }^{84,85}$ Their complex care clinic for high-risk elders ( 3 or more chronic conditions that worsen over time) opened in January 2013. Claims data before and after the complex care clinic opened for all high-risk elders in a 3-physician practice were compared with patients receiving usual care from 20 providers in different geographic locations. The intervention group had a $30 \%$ decrease in emergency department (ED) use and $43 \%$ decrease in acute admissions. Increased consultation duration enabled more in-depth assessment and ability to address all chronic conditions during visits as well as improving billing and coding (and thus increasing payments).

\section{Observational Studies on Consultation Duration and Patient Outcomes}

North Carolina

The North Carolina study sampled 869 patients ( $90 \%$ white, median age 49$)$ and obtained outcome data from medical records on receipt of general physical exams, diabetes follow-up care, initial evaluation for hypertensives, or care for acute dysuria (women). ${ }^{86}$ Workload was based on physician-reported number of patients seen per hour over a typical 2-week period, validated by data from office staff. Visit length ranged from 9.3 to 37.5 minutes, and physicians saw 1.6 to 6.4 patients per hour.

\section{Western Washington}

The Group Health Cooperative of Puget Sound serves 245,000 enrollees. ${ }^{87}$ Average patient panel size was 1,600 , with 355 mean patient contacts (visits) per month, an average consultation duration of 17.8 minutes (range: 13.3 to 26.1 minutes), and 3.4 patients seen per hour. Older panel age (\% over 40) explained $23 \%$ of the variance, followed by number of patients seen per hour and visits per month (18\% combined; $14 \%$ and $4 \%$, respectively), and interclinic differences (8\%).

\section{Pennsylvania}

The evaluation of Pennsylvania primary care clinics occurred over 7 months for 4695 medical encounters of 1424 patients seen by 64 physicians. ${ }^{88}$ Average consultation duration was 17 minutes (range 10 to 60 ). Physicians saw a mean of 3.6 patients per hour (range 1 to 6). Physicians were evaluated in 7 composite care delivery areas identified via factor analysis: blood chemistry, blood counts, inconsistency of test ordering, visit frequency, immunizations, medical history items, and preventive care for women.

Patients of busier physicians were significantly more likely to receive procedures (such as weight check, blood pressure measurement and blood count, and medication review) from support staff. Patients of busier physicians, characterized as more than 4 patients/hour, had more frequent visits and shorter intervals between visits. Physicians who saw 3 or more patients per hour often took less complete medical histories and were less likely to provide preventive care specifically for women. Those seeing 2.9 or more patients per hour less often assessed smoking, alcohol use, and family history and conducted fewer Papanicolaou smears and breast exams. Both less (less than 2.7 patients/hour) and more (3.9 to 4.5 patients/hour) burdened physicians conducted fewer blood count procedures.

\section{Limitations: Consultation Features}

Authors of 2 early nonsystematic reviews ${ }^{89,90}$ suggest that what transpires during the visit, rather than the amount of time, is critical. Wilson distinguishes between physician and patient factors that influence consultation length and concludes that physician factors, which he believes are idiosyncratic, account for much of the variance and thus underlie observed associations between duration and patient outcomes. ${ }^{90} \mathrm{~A}$ cross-sectional study between 1996 and 1999 of 6 European countries found that patient factors explained more of the variation in consultation duration $(55 \%)$ than physician factors $(22 \%)$, and country factors $(23 \%)$ based on data from questionnaires and 
videotaped encounters among 190 general practitioners and 15 patients of each practitioner (3764 patients). ${ }^{91}$ Median consultation duration varied widely by country: 7.6 to 15.6 minutes; 10.7 minutes overall.

Authors of a 1987 observational study of consultation duration in Scotland suggest consultation style rather than duration is more important to outcomes. ${ }^{66}$ Based on their classification of 85 general practitioners by work style for 21,707 consultations on 1 day in every 15 over the course of a year, slower doctors who worked fast were similar to faster doctors. Slower doctors were not faster doctors who worked more slowly, rather consultation duration dropped with larger panels, suggesting that the ratio of long to short consultations is an important proxy for quality of care.
How consultation time is spent differs by country: by 2010, US physicians reported needing approximately 2 to 3 times longer to provide high-quality care for new patient appointments, routine consultations, and complete physicals compared with their German and UK counterparts. ${ }^{92}$ Although the UK and several other countries have significantly larger patient panels and shorter patient consultations, in the US higher EHR demands minimize the available time within consultations for focused, high-quality communication. Increased protected time for physician-patient interaction might improve the qualitative experience, diagnosis, and management and thereby decrease costs. Decreasing unnecessary and redundant EHR tasks will reduce EHR burden and free up physician time. $^{93,94}$ 


\section{Appendix References}

1. Osborn R, Moulds D, Schneider EC, Doty MM, Squires D, Sarnak DO. Primary care physicians in ten countries report challenges caring for patients with complex health needs. Health Aff (Millwood) 2015;34:2104-12. Available from: https:/www. healthaffairs.org/doi/10.1377/hlthaff.2015.1018? url_ver=Z39.88-2003\&rfr_id=ori:rid:crossref.org\& rfr_dat=cr_pub\%20\%200pubmed. Accessed April 28, 2021.

2. Robert Wood Johnson Foundation. 2011 physicians' daily life report. November 15, 2011. Available from: https://www.issuelab.org/resources/12550/12550. pdf. Accessed January 7, 2021.

3. Regina Corso Consulting. 2017 patient survey report for the Physicians Foundation. June 2017. Available from: https://physiciansfoundation.org/ wp-content/uploads/2017/12/Physicians_Foundation_ 2017_Patient_Survey_Report.pdf. Accessed January 11, 2021.

4. Merritt Hawkins. 2016 survey of America's physicians: practice patterns and perspectives. The Physicians Foundation; September 2016. Available from: https://physiciansfoundation.org/wp-content/ uploads/2017/12/Biennial_Physician_Survey_2016. pdf. Accessed January 11, 2021.

5. Downing NL, Bates DW, Longhurst CA. Physician burnout in the electronic health record era: are we ignoring the real cause? Ann Intern Med 2018;169:50-1. Available from: https:// annals.org/aim/article-abstract/2680726/physicianburnout-electronic-health-record-era-we-ignoringreal-cause. Accessed January 7, 2021.

6. Hunt LM, Bell HS, Baker AM, Howard HA. Electronic health records and the disappearing patient. Med Anthropol Q 2017;31:403-21. Available from: https://www.ncbi.nlm.nih.gov/pmc/ articles/PMC6104392/. Accessed February 1, 2021.

7. Irving G, Neves AL, Dambha-Miller H, et al. International variations in primary care physician consultation time: a systematic review of 67 countries. BMJ Open 2017;7:e017902. Available from: https://bmjopen.bmj.com/content/bmjopen/7/10/ e017902.full.pdf?with-ds=yes. Accessed January 28, 2021.

8. Marx R, Kahn JG. Increased U.S. primary care consultation duration due to EHR burden? BMJ Open; June 1, 2018; comment on Irving et al. Available from: https://bmjopen.bmj.com/content/ 7/10/e017902.responses. Accessed January 11, 2021.

9. Tai-Seale M, Olson CW, Li J, et al. Electronic health record logs indicate that physicians split time evenly between seeing patients and desktop medicine. Health Aff (Millwood) 2017;36:655-62. Available from: https://www.ncbi.nlm.nih.gov/ pmc/articles/PMC5546411/. Accessed February 9, 2021.
10. Arndt BG, Beasley JW, Watkinson MD, et al. Tethered to the EHR: primary care physician workload assessment using EHR event log data and time-motion observations. Ann Fam Med 2017;15:419-26. Available from: https://www.ncbi. nlm.nih.gov/pmc/articles/PMC5593724/. Accessed January 6, 2021.

11. Sinsky C, Colligan L, Li L, et al. Allocation of physician time in ambulatory practice: a time and motion study in 4 specialties. Ann Intern Med 2016;165:753-60. Available from: https://www. acpjournals.org/doi/10.7326/M16-0961?url_ver= Z39.88-2003\&rfr_id=ori:rid:crossref.org\&rfr_dat= cr_pub\%20\%200pubmed. Accessed January 6, 2021.

12. Merritt Hawkins. 2018 survey of America's physicians: practice patterns and perspectives; an examination of the professional morale, practice patterns, career plans, and perspectives of today's physicians, aggregated by age, gender, primary care/specialists and practice owners/employees. The Physicians Foundation; September 2018. Available from: https://physiciansfoundation.org/ wp-content/uploads/2018/09/physicians-surveyresults-final-2018.pdf. Accessed February 1, 2021.

13. Street RL, Jr, Liu L, Farber NJ, et al. Keystrokes, mouse clicks, and gazing at the computer: how physician interaction with the EHR affects patient participation. J Gen Intern Med 2018;33:423-8. Available from: https://link.springer.com/article/ 10.1007/s11606-017-4228-2. Accessed Februrary 2, 2021.

14. Bodenheimer T. Primary care-will it survive? N Engl J Med 2006;355:861-4. Available from: https:// www.nejm.org/doi/10.1056/NEJMp068155. Accessed January 11, 2021.

15. AAMC 2018. The complexities of physician supply and demand: projections from 2018 to 2033; June 2020. Available from: https://www.aamc.org/ media/45976/download. Accessed January 11, 2021.

16. Sinsky CA, Dyrbye LN, West CP, Satele D, Tutty M, Shanafelt TD. Professional satisfaction and the career plans of US physicians. Mayo Clin Proc 2017;92:1625-35. Available from: https:// www.mayoclinicproceedings.org/article/S00256196(17)30637-7/fulltext. Accessed January 11, 2021.

17. Zallman L, Finnegan K, Roll D, Todaro M, Oneiz $\mathrm{R}$, Sayah A. Impact of medical scribes in primary care on productivity, face-to-face time, and patient comfort. J Am Board Fam Med 2018;31:612-9. Available from: https://www.jabfm.org/content/ 31/4/612.long. Accessed February 8, 2021.

18. Ghorob A, Bodenheimer T. Share the Care ${ }^{\mathrm{TM}}$ : building teams in primary care practices. J Am Board Fam Med 2012;25:143-5. Available from: 
https://www.jabfm.org/content/25/2/143.long. Accessed January 12, 2021.

19. Sinsky CA, Willard-Grace R, Schutzbank AM, Sinsky TA, Margolius D, Bodenheimer T. In search of joy in practice: a report of 23 high-functioning primary care practices. Ann Fam Med 2013;11:272-8. Available from: https:/www.ncbi. nlm.nih.gov/pmc/articles/PMC3659145/. Accessed January 12, 2021.

20. Sinsky CA, Bodenheimer T. Powering-up primary care teams: advanced team care with in-room support. Ann Fam Med 2019;17:367-71. Available from: https://www.annfammed.org/content/17/4/ 367. Accessed January 12, 2021.

21. Hochmann and Cohen's Slow Medicine blog. Available from: https://centerforhealthjournalism. org/blog-category/slow-medicine. Accessed February $15,2021$.

22. Wolfson D, Santa J, Slass L. Engaging physicians and consumers in conversations about treatment overuse and waste: a short history of the Choosing Wisely campaign. Acad Med 2014;89:990-5. Available from: https://journals.lww.com/academic medicine/Fulltext/2014/07000/Engaging_Physicians_ and_Consumers_in_Conversations.17.aspx. Accessed January 12, 2021.

23. Welch HG, Schwartz LM, Woloshin S. Overdiagnosed: making people sick in the pursuit of health. Boston (MA): Beacon Press, 2012.

24. Welch HG. Less medicine, more health; 7 assumptions that drive too much medical care. Boston (MA): Beacon Press, 2015.

25. Brownlee S. Overtreated-why too much Medicine is making us sicker and poorer. New York: Bloomsbury, 2007.

26. Gawande A. Overkill. New Yorker. May 4, 2015. Available from: https://www.newyorker. com/magazine/2015/05/11/overkill-atul-gawande. Accessed January 8, 2021.

27. Kleinert S, Horton R. From universal health coverage to right care for health. Lancet 2017; 390:101-2. Available from: https://www.thelancet. com/journals/lancet/article/PIIS0140-6736(16) 32588-0/fulltext. Accessed February 9, 2021.

28. Zaharias G. What is narrative-based medicine? Narrative-based medicine 1. Can Fam Physician 2018;64:176-80. Available from: https://www. ncbi.nlm.nih.gov/pmc/articles/PMC5851389/. Accessed January 12, 2021.

29. Halpern J. From detached concern to empathy: humanizing medical practice. New York: Oxford University Press 2001.

30. Leppin AL, Montori VM, Gionfriddo MR. Minimally disruptive medicine: a pragmatically comprehensive model for delivering care to patients with multiple chronic conditions. Healthcare (Basel) 2015;3:50-63. Available from: https://www.mdpi. com/2227-9032/3/1/50/htm. Accessed January 12, 2021.

31. Wen LS, Kosowsky JM. When doctors don't listen: how to avoid misdiagnoses and unnecessary tests. New York: Thomas Dunne Books/St. Martin's Press, 2013.

32. Montori $\mathrm{V}$. Why we revolt: a patient revolution for careful and kind care. Rochester, MN: Mayo Clinic Press, 2020.

33. Zulman DM, Haverfield MC, Shaw JG, et al. Practices to foster physician presence and connection with patients in the clinical encounter. JAMA 2020;323:70-81. Available from: https://jamanetwork. com/journals/jama/article-abstract/2758456? guest AccessKey=391616d7-b6ad-4648-a08d-4381e92868a $8 \&$ utm_source=For_The_Media. Accessed January 12, 2021.

34. Costanzo C, Verghese A. The physical examination as ritual: social sciences and embodiment in the context of the physical examination. Med Clin North Am 2018;102:425-31. PMID: 29650064. Available from: https://pubmed.ncbi. nlm.nih.gov/29650064/. Accessed February 2, 2021.

35. Verghese A. The importance of being. Health Aff (Millwood) 2016;35:1924-7.Oct 1. Available from: https://www.healthaffairs.org/doi/10.1377/hlthaff. 2016.0837?url_ver=Z39.88-2003\&rfr_id=ori:rid: crossref.org\&rfr_dat=cr_pub\%20\%200pubmed. Accessed February 2, 2021.

36. Shanafelt TD, Dyrbye LN, West CP. Addressing physician burnout: the way forward. JAMA 2017; 317:901-2. Available from: https://jamanetwork.com/ journals/jama/article-abstract/2603408. Accessed February 9, 2021.

37. Panagioti M, Panagopoulou E, Bower P, et al. Controlled interventions to reduce burnout in physicians: a systematic review and meta-analysis. JAMA Intern Med 2017;177:195-205. Available from: https://jamanetwork.com/journals/jamainternal medicine/article-abstract/2588814. Accessed February 9, 2021.

38. Sweet V. God's hotel: a doctor, a hospital and a pilgrimage to the heart of medicine. New York: Riverhead Books, 2012.

39. Lown B. The lost art of healing: practicing compassion in medicine. New York: Houghton Mifflin, 1996.

40. Sweet V. Slow medicine: the way to healing. New York: Riverhead Books, 2017.

41. McCullough D. My mother, your mother: embracing "slow medicine," the compassionate approach to caring for your aging loved ones. New York: HarperCollins, 2008.

42. Butler KA. Knocking on heaven's door: the path to a better way of death. New York: Scribner, 2013. 
43. Aronson LE. Redefining aging, transforming medicine, reimagining life. New York: Bloomsbury Publishing, 2019.

44. Gawande A. Being mortal: medicine and what matters in the end. New York: Metropolitan Books, 2014.

45. Meltzer D, Cursio J, Flores A, et al. Effects of a comprehensive care physician (ccp) program on patient satisfaction, health status, and hospital admissions in Medicare patients at increased risk of hospitalization: initial findings of a randomized trial. Abstract. Academy Health Annual Research Meeting. June 24-26, 2018. Seattle, WA. Available from: https:// academyhealth.confex.com/academyhealth/2018arm/ meetingapp.cgi/Paper/23609. Accessed January 18, 2021.

46. Edwards ST, Peterson K, Chan B, Anderson J, Helfand M. Effectiveness of intensive primary care interventions: a systematic review. J Gen Intern Med 2017;32:1377-86. Available from: https:// www.ncbi.nlm.nih.gov/pmc/articles/PMC5698228/. Accessed January 18, 2021.

47. Chase D. On retainer: direct primary care practices bypass insurance. California HealthCare Foundation; April 2013. Available from: https:// www.chcf.org/wp-content/uploads/2017/12/PDFOnRetainerDirectPrimaryCare.pdf. Accessed January 20, 2021.

48. Huff C. Direct primary care: concierge care for the masses. Health Aff (Millwood) 2015;34:20169. Available from: https://www.healthaffairs.org/ doi/full/10.1377/hlthaff.2015.1281. Accessed January 22, 2021.

49. Rowe K, Rowe W, Umbehr J, Dong F, Ablah E. Direct primary care in 2015: a survey with selected comparisons to 2005 survey data. Kans J Med 2017;10:3-6. Available from: https://www.ncbi. nlm.nih.gov/pmc/articles/PMC5733409/. Accessed January 20, 2021.

50. DPC Frontier. Available from: https://mapper. dpcfrontier.com/. Accessed January 20, 2021.

51. Eskew PM, Klink K. Direct primary care: practice distribution and cost across the nation. J Am Board Fam Med 2015;28:793-801. Available from: https://www.jabfm.org/content/28/6/793.long. Accessed January 20, 2021.

52. Edwards A. Direct primary care: a snapshot. American Academy of Family Physicians Foundation; August 20, 2019. Available from: https:/www.aafp.org/news/blogs/freshperspectives/ entry/20190820fp-dpcsnapshot.html. Accessed January 20, 2021.

53. Eskew P. In defense of direct primary care. Fam Pract Manag 2016;23:12-4. Available from: https://www.aafp.org/fpm/2016/0900/p12.html. Accessed January 20, 2021.

54. Al-Agba N. Is the direct primary care model dead? The Health Care Blog; June 16, 2016. Available from: http://thehealthcareblog.com/blog/2017/06/ 06/is-the-direct-primary-care-model-dead/. Accessed January 20, 2021.

55. Krivic RS. Is the DPC movement at risk of failing? Medical Economics May 21, 2017. Available from: https://www.medicaleconomics.com/view/dpcmovement-risk-failing. Accessed January 20, 2021.

56. Pflanzer LR. A new kind of doctor's office that doesn't take insurance and charges a monthly fee is "popping up everywhere"-and that could change how we think about healthcare. Business Insider March 19, 2017. Available from: https:// www.businessinsider.com/direct-primary-care-ano-insurance-healthcare-model-2017-3. Accessed January 20, 2021.

57. Irving G, Neves AL, Dambha-Miller H, et al. International variations in primary care physician consultation time: a systematic review of 67 countries. BMJ Open 2017;7:e017902. Available from: http://bmjopen.bmj.com/content/7/10/e017902. long. Accessed January 11, 2021.

58. Wilson AD, Childs S, Gonçalves-Bradley DC, Irving GJ, Cochrane Effective Practice and Organisation of Care Group. Interventions to increase or decrease the length of primary care physicians' consultation. Cochrane Database Syst Rev 2016;8:CD003540. Available from: https:// www.cochranelibrary.com/cdsr/doi/10.1002/14651858. CD003540.pub3/epdf/full. Accessed 29 January 2021.

59. Wilson A, Childs S. The effect of interventions to alter the consultation length of family physicians: a systematic review. Br J Gen Pract 2006;56:876-82. Available from: https://www.ncbi.nlm.nih.gov/pmc/ articles/PMC1927097/. Accessed January 28, 2021.

60. Wilson A, Childs S. The relationship between consultation length, process and outcomes in general practice: a systematic review. Br J Gen Pract 2002;52:1012-20. Available from: https://www. ncbi.nlm.nih.gov/pmc/articles/PMC1314474/pdf/ 12528590.pdf. Accessed January 28, 2021.

61. Morrell DC, Evans ME, Morris RW, Roland MO. The "five minute" consultation: effect of time constraint on clinical content and patient satisfaction. Br Med J (Clin Res Ed) 1986;292:870-3. Available from: https://www.ncbi.nlm.nih.gov/ pmc/articles/PMC1339979/pdf/bmjcred002270028.pdf. Accessed January 28, 2021.

62. Ridsdale L, Carruthers M, Morris R, Ridsdale J. Study of the effect of time availability on the consultation. J R Coll Gen Pract 1989;39:488-91. Available from: https://www.ncbi.nlm.nih.gov/ pmc/articles/PMC1712205/. Accessed January 28, 2021.

63. Thomas KB. Time and the consultation in general practice. Br Med J 1978;2:1000. Available from: https://www.ncbi.nlm.nih.gov/pmc/articles/ PMC1607875/. Accessed January 28, 2021. 
64. Wilson A, McDonald P, Hayes L, Cooney J. Health promotion in the general practice consultation: a minute makes a difference. BMJ 1992;304:227-30. Available from: https:/www. ncbi.nlm.nih.gov/pmc/articles/PMC1881485/pdf/ bmj00057-0037.pdf. Accessed January 28, 2021.

65. Campbell SM, Hann M, Hacker J, et al. Identifying predictors of high quality care in English general practice: observational study. BMJ 2001;323:784-7. Available from: https://www.ncbi. nlm.nih.gov/pmc/articles/PMC57358/. Accessed January 28, 2021.

66. Howie JG, Porter AM, Heaney DJ, Hopton JL. Long to short consultation ratio: a proxy measure of quality of care for general practice. Br J Gen Pract 1991;41:48-54. Available from: https://www. ncbi.nlm.nih.gov/pmc/articles/PMC1371550/pdf/ brigenprac00071-0006.pdf. Accessed January 28, 2021.

67. Hughes D. Consultation length and outcome in two group general practices. J R Coll Gen Pract 1983;33:143-7. Available from: https:/www.ncbi. nlm.nih.gov/pmc/articles/PMC1972718/pdf/jroyalcg prac00075-0017.pdf. Accessed January 28, 2021.

68. Davidson W, Molloy DW, Somers G, Bédard M. Relation between physician characteristics and prescribing for elderly people in New Brunswick. CMAJ 1994;150:917-21. Available from: https:// www.ncbi.nlm.nih.gov/pmc/articles/PMC1486694/ pdf/cmaj00286-0113.pdf. Accessed January 28, 2021.

69. Tamblyn R, Berkson L, Dauphinee WD, et al. Unnecessary prescribing of NSAIDs and the management of NSAID-related gastropathy in medical practice. Ann Intern Med 1997;127:429-38. Available from: https://www.acpjournals.org/doi/10.7326/00034819-127-6-199709150-00003?url_ver=Z39.88-2003 \&rfr_id=ori\%3Arid\%3Acrossref.org\&rfr_dat= cr_pub ++0pubmed \&. Accessed January 28, 2021.

70. Mercer SW, Fitzpatrick B, Guthrie B, et al. The CARE Plus study-a whole-system intervention to improve quality of life of primary care patients with multimorbidity in areas of high socioeconomic deprivation: exploratory cluster randomised controlled trial and cost-utility analysis. BMC Med 2016;14:88. Available from: https://www. ncbi.nlm.nih.gov/pmc/articles/PMC4916534/. Accessed January 28, 2021.

71. Klemes A, Seligmann RE, Allen L, Kubica MA, Warth K, Kaminetsky B. Personalized preventive care leads to significant reductions in hospital utilization. Am J Manag Care 2012;18:e45360. Available from: https://www.ajmc.com/view/ personalized-preventive-care-leads-to-significantreductions-in-hospital-utilization. Accessed January 20, 2021.

72. Musich S, Wang S, Hawkins K, Klemes A. The Impact of Personalized Preventive Care on Health
Care Quality, Utilization, and Expenditures. Popul Health Manag 2016;19:389-97.Dec. Epub 2016 Feb 12. PMID: 26871762; PMCID: PMC5296930. Available from: https://www.ncbi.nlm.nih.gov/pmc/ articles/PMC5296930/. Accessed January 22, 2021.

73. Wu WN, Bliss G, Bliss EB, Green LA. Practice profile. A direct primary care medical home: the Qliance experience. Health Aff (Millwood) 2010;29:959-62. Available from: https://www. healthaffairs.org/doi/full/10.1377/hlthaff.2010.0047? cited-by=yes\&. Accessed January 22, 2021.

74. Qliance Medical Group. Online table; 2010. Available from: https://b-i.forbesimg.com/davechase/ files/2013/07/DPC-Qliance-reduction-in-down stream-care.jpg. Accessed January 22, 2021.

75. Qliance. New primary care model delivers 20 percent lower overall healthcare costs, increases patient satisfaction and delivers better care; January 15, 2015. Available from: http://www. prnewswire.com/news-releases/new-primary-caremodel-delivers-20-percent-lower-overall-healthcarecosts-increases-patient-satisfaction-and-deliversbetter-care-300021116.html. Accessed January 22, 2021.

76. Govindarajan V, Ramamurti R. Transforming health care from the ground up. Harvard Business Review Magazine July-Aug 2018. Available from: https://hbr.org/2018/07/transforming-health-carefrom-the-ground-up. Accessed January 22, 2021.

77. Shemkus S. Iora Health's promise: patients come first. Boston Globe May 4, 2015. Available from: https://www.bostonglobe.com/business/2015/05/ 03/iora-health-pioneers-new-primary-care-model/ kc7V4W5V8OJ0gxFqY4zBrK/story.html. Accessed January 22, 2021.

78. Schiff J. Best practices: from the bottom up, Iora Health helps providers build ACO framework. Modern Healthcare June 18, 2016. Available from: https://www.modernhealthcare.com/article/2016 0618/MAGAZINE/306189997/iora-health-helpingproviders-invert-aco-models. Accessed January 22, 2021.

79. Brubaker H. This Elkins Park Company has a plan to reduce employees' health-care costs. Philadelphia Inquirer January 28, 2019. Available from: https://www.philly.com/business/directprimary-care-r-health-pareto-captive-philadelphianew-jersey-20190128.html. Accessed January 22, 2021.

80. Tanio C, Chen C. Innovations at Miami practice show promise for treating high-risk Medicare patients. Health Aff (Millwood) 2013;32:1078-82. Available from: https://www.healthaffairs.org/doi/ pdf/10.1377/hlthaff.2012.0201. Accessed January 22, 2021.

81. Ghany R, Tamariz L, Chen G, et al. High-touch care leads to better outcomes and lower costs in a senior population. Am J Manag Care 2018;Sep 
124:e300-e304. Available from: https://www.ajmc. com/view/hightouch-care-leads-to-better-outcomesand-lower-costs-in-a-senior-population. Accessed January 22, 2021.

82. Chen C. How concierge care for low-income seniors can improve outcomes and reduce costs. Am J Manag Care; September 25, 2017. Available from: https://www.ajmc.com/view/how-conciergecare-for-low-income-seniors-can-improve-outcomesand-reduce-costs. Accessed April 28, 2021.

83. Phillips RL, Jr, Bronnikov S, Petterson S, et al. Case study of a primary care-based accountable care system approach to medical home transformation. J Ambul Care Manage 2011;34:67-77. Available from: https://journals.lww.com/ambulatorycare management/Abstract/2011/01000/Case_Study_ of_a_Primary_Care_Based_Accountable.9.aspx. Accessed January 22, 2021.

84. Institute for Healthcare Improvement. Signature Healthcare: a triple aim improvement story. Cambridge, MA: Institute for Healthcare Improvement; October 2015. Available from: http://www. ihi.org/resources/Pages/Publications/Signature HealthcareTripleAim.aspx. Accessed January 22, 2021.

85. Whittington JW, Nolan $\mathrm{K}$, Lewis N, Torres T. Pursuing the triple aim: the first 7 years. Milbank Q 2015;93:263-300. Available from: https://www. ncbi.nlm.nih.gov/pmc/articles/PMC4462878/. Accessed January 22, 2021.

86. Hulka BS, Romm FJ, Parkerson GR, Jr, Russell IT, Clapp NE, Johnson FS. Peer review in ambulatory care: use of explicit criteria and implicit judgments. Med Care 1979;17:1-73. Available from: https://www.ncbi.nlm.nih.gov/pubmed/763009. Accessed January 28, 2021.

87. Hartzema AG, Christensen DB. Nonmedical factors associated with the prescribing volume among family practitioners in an HMO. Med Care 1983;21:9901000. Available from: https://journals.lww.com/lwwmedicalcare/Abstract/1983/10000/Nonmedical_
Factors_Associated_With_the_Prescribing.5.aspx. Accessed January 28, 2021.

88. Camasso MJ, Camasso AE. Practitioner productivity and the product content of medical care in publicly supported health centers. Soc Sci Med 1994;38:733-48. Available from: https://www.sciencedirect.com/science/article/ abs/pii/0277953694904642. Accessed January 28, 2021.

89. Dugdale DC, Epstein R, Pantilat SZ. Time and the patient-physician relationship. J Gen Intern Med 1999;14:S34-40. Available from: https:// www.ncbi.nlm.nih.gov/pmc/articles/ PMC1496869/. Accessed January 28, 2021.

90. Wilson A. Consultation length in general practice: a review. Br J Gen Pract 1991;41:119-22. Available from: https://www.ncbi.nlm.nih.gov/pmc/articles/ PMC1371626/. Accessed January 28, 2021.

91. Deveugele $M$, Derese A, van den Brink-Muinen A, Bensing J, De Maeseneer J. Consultation length in general practice: cross sectional study in six European countries. BMJ 2002;325:472. Available from: https:/www.ncbi.nlm.nih.gov/pmc/articles/ PMC119444/. Accessed February 4, 2021.

92. Konrad TR, Link CL, Shackelton RJ, et al. It's about time: physicians' perceptions of time constraints in primary care medical practice in three national healthcare systems. Med Care 2010;48:95-100. Available from: https://www. ncbi.nlm.nih.gov/pmc/articles/PMC3621071/pdf/ nihms454710.pdf. Accessed January 28, 2021.

93. Sinsky CA, Privitera MR. Creating a "manageable cockpit" for clinicians: a shared responsibility. JAMA Intern Med 2018;178:741-2. Available from: https://jamanetwork.com/journals/jamainternal medicine/article-abstract/2674872. Accessed January 28, 2021.

94. Ashton M. Getting rid of stupid stuff. N Engl J Med 2018;379:1789-91. Available from: https:// www.nejm.org/doi/full/10.1056/NEJMp1809698. Accessed January 28, 2021. 